\title{
Intermodel Spread in the Pattern Effect and Its Contribution to Climate Sensitivity in CMIP5 and CMIP6 Models
}

\author{
Yue Dong, ${ }^{\mathrm{a}}$ Kyle C. Armour, ${ }^{\mathrm{a}, \mathrm{b}}$ Mark D. Zelinka, ${ }^{\mathrm{c}}$ Cristian Proistosescu, ${ }^{\mathrm{d}}$ \\ DAVID S. BATTISTI, ${ }^{\mathrm{a}}$ CHEN ZHOU, ${ }^{\mathrm{e}}$ AND TIMOTHY ANDREWS ${ }^{\mathrm{f}}$ \\ ${ }^{a}$ Department of Atmospheric Sciences, University of Washington, Seattle, Washington \\ ${ }^{b}$ School of Oceanography, University of Washington, Seattle, Washington \\ ${ }^{c}$ Lawrence Livermore National Laboratory, Livermore, California \\ ${ }^{d}$ Department of Atmospheric Sciences and Department of Geology, University of Illinois at Urbana-Champaign, \\ Urbana, Illinois \\ ${ }^{e}$ Department of Atmospheric Physics, Nanjing University, Nanjing, China \\ ${ }^{f}$ Met Office Hadley Centre, Exeter, United Kingdom
}

(Manuscript received 30 December 2019, in final form 15 June 2020)

\begin{abstract}
Radiative feedbacks depend on the spatial patterns of sea surface temperature (SST) and thus can change over time as SST patterns evolve-the so-called pattern effect. This study investigates intermodel differences in the magnitude of the pattern effect and how these differences contribute to the spread in effective equilibrium climate sensitivity (ECS) within CMIP5 and CMIP6 models. Effective ECS in CMIP5 estimated from 150 -yr-long abrupt $4 \times \mathrm{CO} 2$ simulations is on average $10 \%$ higher than that estimated from the early portion (first 50 years) of those simulations, which serves as an analog for historical warming; this difference is reduced to $7 \%$ on average in CMIP6. The (negative) net radiative feedback weakens over the course of the abrupt $4 \times \mathrm{CO} 2$ simulations in the vast majority of CMIP5 and CMIP6 models, but this weakening is less dramatic on average in CMIP6. For both ensembles, the total variance in the effective ECS is found to be dominated by the spread in radiative response on fast time scales, rather than the spread in feedback changes. Using Green's functions derived from two AGCMs shows that the spread in feedbacks on fast time scales may be primarily due to differences in atmospheric model physics, whereas the spread in feedback evolution is primarily governed by differences in SST patterns. Intermodel spread in feedback evolution is well explained by differences in the relative warming in the west Pacific warm-pool regions for the CMIP5 models, but this relation fails to explain differences across the CMIP6 models, suggesting that a stronger sensitivity of extratropical clouds to surface warming may also contribute to feedback changes in CMIP6.
\end{abstract}

\section{Introduction}

Uncertainty in estimates of equilibrium climate sensitivity (ECS) - the equilibrium surface temperature change in response to a doubling of $\mathrm{CO}_{2}$ above preindustrial levels-has long been linked to uncertainty in the radiative feedbacks $\lambda$ that govern the efficiency with which the climate system radiates energy to space per degree of surface warming. The strength of $\lambda$ is intrinsically set by blackbody radiation, which is further modulated by radiative feedbacks associated with changes in atmospheric lapse rate, water vapor, surface albedo, and clouds. Among these, the cloud feedback has been found to be the primary source of ECS uncertainty (Webb et al. 2006; Soden and Held 2006;

\footnotetext{
Corresponding author: Yue Dong, dongy24@uw.edu
}

Dufresne and Bony 2008; Webb et al. 2013; Caldwell et al. 2016; Zelinka et al. 2016; Ceppi et al. 2017; Caldwell et al. 2018; Zelinka et al. 2020). The low-cloud feedback is particularly uncertain (Bony and Dufresne 2005; Webb et al. 2006, 2015; Ceppi et al. 2017), leading to tremendous efforts in the community to constrain it (Bony et al. 2006).

Within global climate models (GCMs), ECS is often estimated based on a standard linear framework for global energy balance:

$$
\begin{aligned}
N & =F+\lambda T, \\
\mathrm{ECS} & =T_{\text {eq }}=-F_{2 \times} / \lambda_{\text {eq }},
\end{aligned}
$$

where $F$ is the effective radiative forcing (with $F_{2 \times}$ representing forcing from $\mathrm{CO}_{2}$ doubling), and where the subscript "eq" denotes the equilibrium state when $N$ 
approaches zero. All variables represent global-mean anomalies with respect to a preindustrial state. A useful method to derive $\lambda$ and ECS from simulations of abrupt $\mathrm{CO}_{2}$ doubling or quadrupling is proposed by Gregory et al. (2004), regressing net TOA radiation imbalance $N$ against surface air temperature change $T$ (hereafter referred to as Gregory $N-T$ regression, with the graphical illustration of this regression referred to as a Gregory plot). This method has been widely used to provide estimates of $\lambda$ (regression slope), $F_{2 \times}$ (from the $y$-axis intercept), and ECS (from the $x$-axis intercept), but is only valid under the assumption that $\lambda$ is constant over time (i.e., $\lambda=\lambda_{\text {eq }}$ at any given time). This general assumption may be violated for several reasons. For example, a discrepancy between $\lambda$ and $\lambda_{\text {eq }}$ may arise from nonlinear state dependence of some feedbacks on global-mean or local temperature (e.g., Block and Mauritsen 2013; Andrews et al. 2015; Bloch-Johnson et al. 2015). For instance, sea ice albedo feedback will become less positive as the amount of sea ice decreases with warming (Goosse et al. 2018) while the water vapor feedback (Meraner et al. 2013) and cloud feedback (Caballero and Huber 2013) may both become more positive with warming. Most importantly, the majority of GCMs in phases 5 and 6 of the Coupled Model Intercomparison Project (CMIP5 and CMIP6) exhibit a weakening of the negative net feedback as time evolves after $\mathrm{CO}_{2}$ forcing is imposed, indicated by a curvature in the Gregory $N-T$ regression (Andrews et al. 2015; Armour 2017; Proistosescu and Huybers 2017; Lewis and Curry 2018). The time dependence of $\lambda$ has been found to arise primarily from its dependence on the spatial pattern of sea surface temperature (SST), which itself can evolve over time (Armour et al. 2013; Zhou et al. 2016; Haugstad et al. 2017; Ceppi and Gregory 2017; Andrews et al. 2018; Dong et al. 2019)—-the so-called pattern effect (Stevens et al. 2016). An important implication is that the climate sensitivity inferred from the historical energy budget is biased low compared to the climate sensitivity estimated over longer time scales under $\mathrm{CO}_{2}$ forcing due to the evolution of surface warming patterns (Armour 2017; Proistosescu and Huybers 2017; Andrews et al. 2018; Marvel et al. 2018; Dong et al. 2019; Gregory et al. 2020; Rugenstein et al. 2020). What is less well understood, however, is what sets the magnitude of the pattern effect, as illustrated by the large intermodel spread in the degree of feedback curvature in the Gregory regression (Andrews et al. 2015; Armour 2017; Ceppi and Gregory 2017). Moreover, the contribution of model spread in feedback curvature to the model spread in ECS estimates has not yet been quantified. This work addresses these two key issues in both CMIP5 and CMIP6 models.
We first present an overview of net feedbacks in CMIP5 and CMIP6 models by showing the Gregory $N-T$ regression for the 150 -yr-long simulations of abrupt $\mathrm{CO}_{2}$ quadrupling (hereafter abrupt $4 \times \mathrm{CO} 2$ ) (Fig. 1). Following Andrews et al. (2015), we calculate radiative feedbacks based on regression over a fast time scale (years 1-20) and over a slow time scale (years 21-150), noted hereafter as $\lambda_{1-20}$ and $\lambda_{21-150}$, respectively. We calculate values of $N$ and $T$ in each model with respect to their preindustrial control simulations (piControl) after accounting for drift by subtracting the linear regression of piControl values over time segment corresponding to the abrupt $4 \times \mathrm{CO} 2$ simulation [following Forster et al. (2013) and Armour (2017)]. All of the anomalies used in this study are annual-mean quantities. Note that we use year 20 to separate the fast response on decadal time scales from the slow response on centennial time scales, following many existing studies, but results are insensitive to the year chosen (Andrews et al. 2015). ECS estimated using the regression method over the course of abrupt $4 \times \mathrm{CO} 2$ simulations is often referred to as the effective equilibrium climate sensitivity (Andrews et al. 2015; Andrews and Webb 2018; Andrews et al. 2018; Gregory et al. 2020), as it presumably differs from the true ECS of the Earth system that would be found by equilibrating over multiple millennia (Rugenstein et al. 2020). In this study, we use several measures of the effective ECS derived from extrapolation of the Gregory $N-T$ regressions to the $x$ axis (divided by 2 to account for $\mathrm{CO}_{2}$ quadrupling) and distinguish them with a subscript denoting the years over which the regression was performed. Specifically, we use $\mathrm{ECS}_{1-20}, \mathrm{ECS}_{21-150}$, and $\mathrm{ECS}_{1-150}$, corresponding to values derived from the regressions over years $1-20$, years $21-150$, and years $1-150$, respectively. Of these three, $\mathrm{ECS}_{21-150}$ provides the most accurate estimate of the true ECS in eight GCMs analyzed by Rugenstein et al. (2020), so we will make this approximation and refer the effective ECS of each model to their $\mathrm{ECS}_{21-150}$ values here.

Figure 1 shows that for both CMIP5 and CMIP6, the ensemble-mean (negative) net feedback weakens toward the longer time scales. That is, there is a positive change in the (negative) net feedback $\left(\Delta \lambda=\lambda_{21-150}-\right.$ $\lambda_{1-20}>0$ ) across 23 of 24 CMIP5 models and 26 of 29 CMIP6 models (see Table 1 for model information), indicating that $\mathrm{ECS}_{1-20}$ is nearly always smaller than ECS $_{21-150}$ in both CMIP5 and CMIP6. Comparing the two ensembles, we find that $\mathrm{ECS}_{1-20}$ and $\mathrm{ECS}_{21-150}$ on average are higher in CMIP6 relative to CMIP5, although they have larger variance in CMIP6 (Fig. 1; Tables 2 and 3). Several up-to-date studies of individual CMIP6 models [Gettelman et al. (2019) for CESM2; Golaz et al. (2019) for E3SM; Sellar et al. (2019) for 
ิ 8 a. CMIP5 Gregory plot
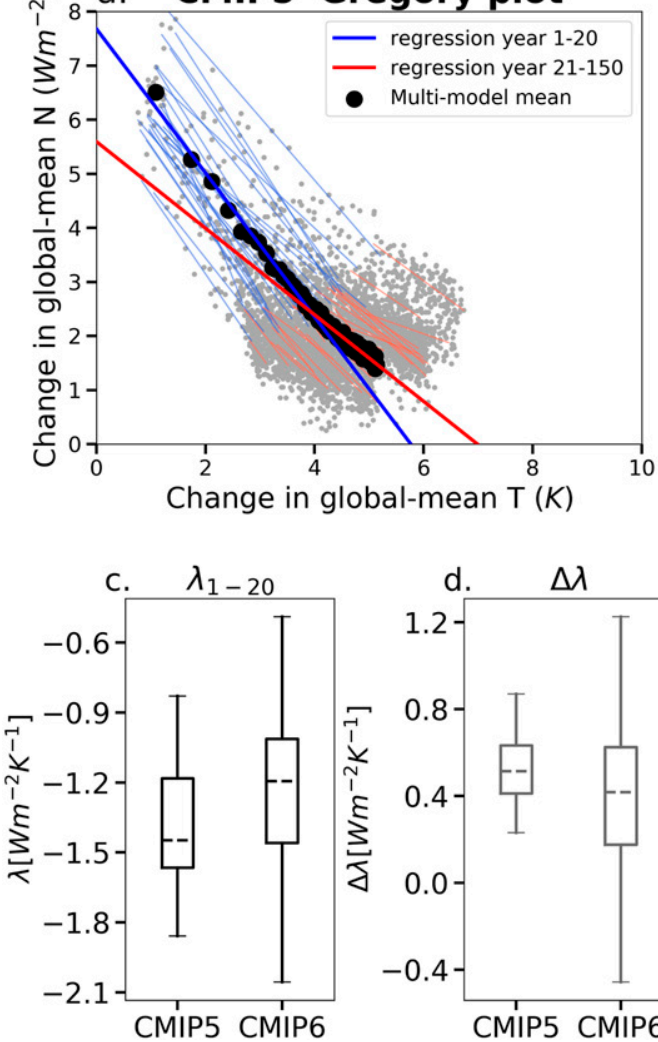

d.

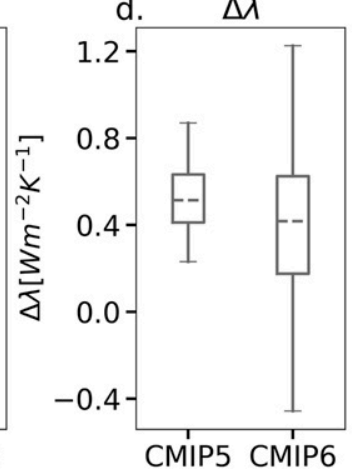

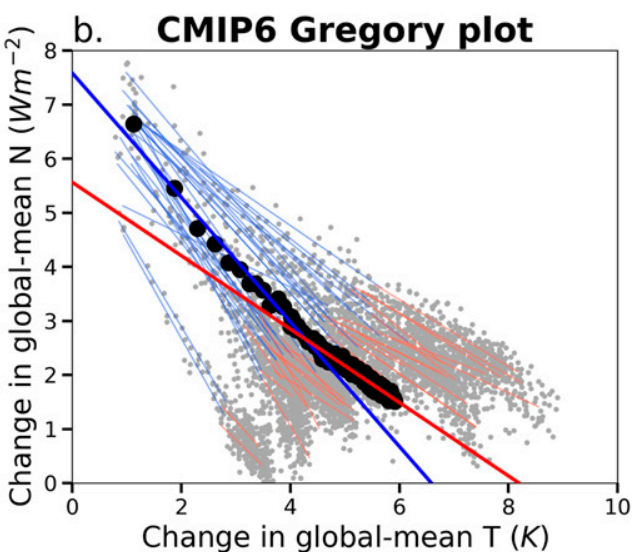

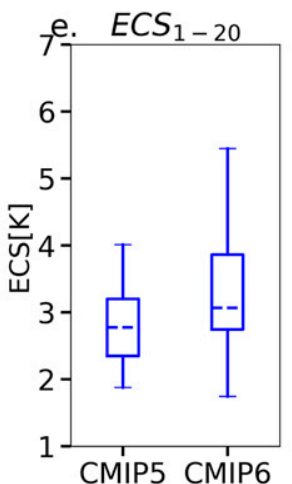

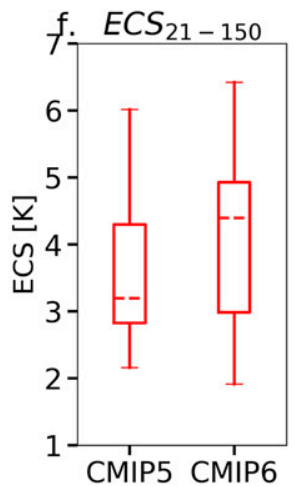

FIG. 1. Gregory plots for (a) CMIP5 and (b) CMIP6: annual-mean change in global-mean net TOA radiation $\left(\mathrm{W} \mathrm{m}^{-2}\right)$ against annual-mean change in global-mean surface air temperature $(\mathrm{K})$ from abrupt $4 \times \mathrm{CO}_{2}$ experiments. Gray dots denote each year from each model; black dots denote each year of multimodel means. Thin (thick) lines show regression fits for years 1-20 (blue) and for years 21-150 (red) for each model (multimodel means). The slope of blue line represents the feedback parameter on the fast time scale $\left(\lambda_{1-20}\right)$, and the slope of red line represents the feedback parameter on the longer time scale $\left(\lambda_{21-150}\right)$. (c)-(f) Box plots of $\lambda_{1-20}\left(\mathrm{~W} \mathrm{~m}^{-2} \mathrm{~K}^{-1}\right), \Delta \lambda\left(\mathrm{W} \mathrm{m}^{-2} \mathrm{~K}^{-1}\right)$, $\mathrm{ECS}_{1-20}(\mathrm{~K})$, and $\mathrm{ECS}_{21-150}(\mathrm{~K})$ in CMIP5 (left box) and CMIP6 (right box) models. The box indicates interquartile range $(\mathrm{IQR})$, the whiskers indicate $1.5 \times \mathrm{IQR}$ range, and the dashed line inside the boxes indicates the median value, for each quantity.

UKESM1; Bodas-Salcedo et al. (2019) for HadGEM3; Andrews et al. (2019) for HadGEM3-GC3.1 and UKESM1] report that the higher values of ECS in their models are largely due to stronger positive cloud feedbacks, which is recently confirmed to be a common feature in the CMIP6 ensemble by Zelinka et al. (2020). Here, by quantifying $\lambda$ on different time scales, we find that both $\lambda_{1-20}$ (feedback strength on the fast time scale) and $\Delta \lambda$ (feedback change over time) are, on average, different in CMIP6 relative to CMIP5 (Fig. 1). Key questions are 1) how do $\lambda_{1-20}$ and $\Delta \lambda$ contribute to the spread in ECS across models and between CMIP5 and CMIP6 ensembles, and how does the pattern effect over historical period change from CMIP5 to CMIP6, 2) what causes the differences in $\Delta \lambda$ across models and between CMIP5 and CMIP6 ensembles, and 3) what physical mechanisms govern $\lambda_{1-20}$ and $\Delta \lambda$.

Motivated by the three questions, we assess the effective ECS, $\lambda_{1-20}$, and $\Delta \lambda$ within 24 CMIP5 models and
29 CMIP6 models (summarized in Table 1). In section 2, we investigate the source of model spread in the effective ECS relating the radiative response on fast time scale and the pattern effect on slow time scale, and also estimate the ECS bias relative to historical estimates in both ensembles. In section 3, we compare the ensemblemean $\Delta \lambda$ in the CMIP5 and CMIP6 models. In section 4, we investigate the intermodel spread in $\lambda_{1-20}$ and $\Delta \lambda$ separately, and track down the key regions of the pattern effect that are most responsible for driving the spread in $\Delta \lambda$ across the CMIP5 and CMIP6 models.

\section{The contribution of the pattern effect to the variance of ECS estimates}

Figure 1d shows that $\Delta \lambda$ is on average smaller in CMIP6 models $\left(0.4 \mathrm{~W} \mathrm{~m}^{-2} \mathrm{~K}^{-1}\right)$ than in CMIP5 models $\left(0.53 \mathrm{~W} \mathrm{~m}^{-2} \mathrm{~K}^{-1}\right)$, despite the fact that $\mathrm{ECS}_{21-150}$ is on 
TABLE 1. The CMIP6 models used in this study.

\begin{tabular}{|c|c|c|}
\hline Institution & CMIP6 model & Data reference \\
\hline CSIRO-ARCCSS & ACCESS-CM2 & Dix et al. 2019 \\
\hline CSIRO & ACCESS-ESM1.5 & Ziehn et al. 2019 \\
\hline $\mathrm{BCC}$ & BCC-CSM2-MR & Wu et al. 2018 \\
\hline $\mathrm{BCC}$ & BCC-ESM1 & Zhang et al. 2018 \\
\hline CAMS & CAMS-CSM1.0 & Rong 2019 \\
\hline $\mathrm{CCCma}$ & CanESM5 & Swart et al. 2019 \\
\hline NCAR & CESM2 & Danabasoglu et al. 2019 \\
\hline NCAR & CESM2-WACCM & Danabasoglu 2019 \\
\hline CNRM & CNRM-CM6.1 & Voldoire 2018 \\
\hline CNRM & CNRM-ESM2.1 & Seferian 2018 \\
\hline E3SM-Project & E3SM-1.0 & Bader et al. 2019 \\
\hline $\begin{array}{l}\text { EC-Earth- } \\
\text { Consortium }\end{array}$ & EC-Earth3-Veg & EC-Earth 2019b \\
\hline $\begin{array}{l}\text { EC-Earth- } \\
\text { Consortium }\end{array}$ & EC-Earth & EC-Earth 2019a \\
\hline NOAA-GFDL & GFDL-CM4 & Guo et al. 2018 \\
\hline NOAA-GFDL & GFDL-ESM4 & Krasting et al. 2018 \\
\hline NASA-GISS & GISS-E2.1-G & NASA/GISS 2018a \\
\hline NASA-GISS & GISS-E2.1-H & NASA/GISS 2018b \\
\hline MOHC & $\begin{array}{c}\text { HadGEM3- } \\
\text { GC31-LL }\end{array}$ & Ridley et al. 2018 \\
\hline INM & INM-CM4.8 & Volodin et al. 2019 \\
\hline INM & INM-CM5.0 & Volodin et al. 2019 \\
\hline IPSL & IPSL-CM6A-LR & Boucher et al. 2018 \\
\hline MIROC & MIROC-ES2L & Hajima et al. 2019 \\
\hline MIROC & MIROC6 & $\begin{array}{l}\text { Tatebe and Watanabe } \\
2018\end{array}$ \\
\hline MRI & MRI-ESM2.0 & Yukimoto et al. 2019 \\
\hline NUIST & NESM3 & Cao and Wang 2019 \\
\hline NCC & NorESM2-LM & Seland et al. 2019 \\
\hline SNU & SAM0-UNICON & Park and Shin 2019 \\
\hline MOHC & UKESM1.0-LL & Tang et al. 2019 \\
\hline
\end{tabular}

average higher in CMIP6 (Fig. 1f) (corresponding to an overall less-negative $\lambda$ ). That is, higher CMIP6-mean effective ECS is not coming from a stronger pattern effect (it is weaker, in fact); it is likely due to lessnegative feedbacks on the fast time scale and stronger radiative forcing (Zelinka et al. 2020). However, there remains the possibility that intermodel spread in $\Delta \lambda$ may contribute to the spread in effective ECS. Therefore, we first estimate the degree to which $\Delta \lambda$ affects the spread in $\mathrm{ECS}_{21-150}$ across models (section 2a). Then we use abrupt $4 \times \mathrm{CO} 2$ simulations as an analog for historical warming [following Lewis and Curry (2018)] to estimate the degree to which the pattern effect causes historical estimates of effective ECS to be less than $\mathrm{ECS}_{21-150}$ (or $\mathrm{ECS}_{1-150}$ ) in CMIP5 and CMIP6 models (section 2b).

\section{a. Correlation between $E C S_{21-150}$ and $E C S_{1-20}$}

Previous studies (Dufresne and Bony 2008; Caldwell et al. 2016) partitioning ECS into components associated with radiative feedbacks and radiative forcing have identified feedbacks as the dominant source of the ECS spread across models. To estimate the relative roles of $\lambda_{1-20}$ and $\Delta \lambda$ in setting ECS, we evaluate the correlation between $\mathrm{ECS}_{21-150}$ and $\mathrm{ECS}_{1-20}$. Without any pattern effect-induced variance, $\mathrm{ECS}_{21-150}$ and $\mathrm{ECS}_{1-20}$ would be highly correlated.

The correlation $\left(r^{2}\right)$ between $\mathrm{ECS}_{21-150}$ and $\mathrm{ECS}_{1-20}$ is 0.69 in CMIP5 and 0.70 in CMIP6, respectively; both correlations are statistically significant at $95 \%$ confidence level. This indicates that the total variance of ECS $_{21-150}$ can be primarily explained by the spread in the radiative response on fast time scales, even without considering the feedback evolution due to the pattern effect. The degree to which feedbacks change over time $(\Delta \lambda)$ thus explains, at most, $30 \%$ of the total variance in ECS in both model ensembles, given the fact that $\lambda_{1-20}$ and $\Delta \lambda$ are weakly correlated $\left(r^{2}=0.3\right.$ for CMIP5 and $r^{2}=0.2$ for CMIP6).

These results suggest that the differences in feedback evolution on longer time scales contribute much less to the spread in $\mathrm{ECS}_{21-150}$ than do the differences in feedbacks on the fast time scales $\left(\lambda_{1-20}\right)$, even though this measure of ECS here is based on the latter period of the abrupt $4 \times \mathrm{CO} 2$ simulations (years 21-150). However, it is worth noting that both in ensemble means and in individual models, $\Delta \lambda$ is generally positive (23 of 24 CMIP5 models and 26 of 29 CMIP6 models), therefore $\mathrm{ECS}_{21-150}$ is nearly always greater than that derived from early portion of the simulation $\left(\mathrm{ECS}_{1-20}\right)$. Thus, while $\lambda_{1-20}$ is the major driver of variance in ECS, ignoring $\Delta \lambda$ and using an assumption of time-invariant feedbacks would lead to a low estimate of the true ECS (as estimated here by $\mathrm{ECS}_{21-150}$ ).

\section{b. ECS-to-ECS $S_{\text {hist }}$ ratio}

As many studies have revealed, the value of ECS estimated from historical energy budget constraints is lower than that based on the behavior of fully coupled and atmosphere-only GCM simulations (Armour 2017; Proistosescu and Huybers 2017; Andrews et al. 2018; Lewis and Curry 2018; Marvel et al. 2018; Gregory et al. 2020). Multiple factors have contributed to the spatial pattern of warming, and thus the pattern effect, over the historical period, including the inherent time scales of ocean adjustment to radiative forcings (e.g., Marvel et al. 2016; Armour 2017; Proistosescu and Huybers 2017) as well as unforced internal climate variability (e.g., Andrews et al. 2018; Marvel et al. 2018). The distinction between forced and unforced pattern effects is further discussed in Dessler (2020). In this section, we consider how the forced pattern effect may bias values of ECS inferred from historical warming based on the behavior of the CMIP5 and CMIP6 models' response to $\mathrm{CO}_{2}$ forcing. 
TABLE 2. Estimates of feedback parameter $\left(\mathrm{W} \mathrm{m}^{-2} \mathrm{~K}^{-1}\right)$ and effective climate sensitivity $(\mathrm{K})$ from abrupt $4 \times \mathrm{CO} 2$ simulations for the CMIP6 GCMs and their multimodel mean. Shown from left to right are feedback parameter over the fast time scale $\left(\lambda_{1-20}\right)$, feedback parameter over the longer time scale $\left(\lambda_{21-150}\right)$, feedback evolution $\left(\Delta \lambda=\lambda_{21-150}-\lambda_{1-20}\right)$, effective climate sensitivity from regressions over years 1-20 $\left(\mathrm{ECS}_{1-20}\right)$, and effective climate sensitivity from regressions over years $21-150\left(\mathrm{ECS}_{21-150}\right)$. All regressions are calculated using the ordinary least squares regression method.

\begin{tabular}{|c|c|c|c|c|c|}
\hline CMIP6 model & $\lambda_{1-20}$ & $\lambda_{21-150}$ & $\Delta \lambda$ & $\mathrm{ECS}_{1-20}$ & $\mathrm{ECS}_{21-150}$ \\
\hline ACCESS-CM2 & -1.1 & -0.5 & 0.6 & 3.75 & 5.41 \\
\hline ACCESS-ESM1-5 & -1.14 & -0.42 & 0.73 & 3.07 & 4.93 \\
\hline BCC-CSM2-MR & -1.26 & -0.63 & 0.64 & 2.85 & 3.5 \\
\hline BCC-ESM1 & -1.25 & -0.74 & 0.51 & 2.78 & 3.5 \\
\hline CAMS-CSM1.0 & -1.94 & -1.71 & 0.24 & 2.23 & 2.31 \\
\hline CESM2-WACCM & -1.11 & -0.48 & 0.63 & 3.65 & 5.49 \\
\hline CESM2 & -1.19 & -0.38 & 0.81 & 3.67 & 6.42 \\
\hline CNRM-CM6.1 & -0.92 & -0.81 & 0.1 & 4.29 & 4.76 \\
\hline CNRM-ESM2.1 & -0.49 & -0.58 & -0.09 & 5.7 & 4.91 \\
\hline CanESM5 & -0.69 & -0.62 & 0.08 & 5.44 & 5.75 \\
\hline E3SM-1.0 & -0.77 & -0.47 & 0.3 & 4.78 & 5.77 \\
\hline EC-Earth3-Veg & -1.12 & -0.7 & 0.42 & 3.57 & 4.45 \\
\hline EC-Earth3 & -1.12 & -0.7 & 0.42 & 3.57 & 4.45 \\
\hline GFDL-CM4 & -1.44 & -0.59 & 0.85 & 2.94 & 4.4 \\
\hline GFDL-ESM4 & -1.36 & -1.46 & -0.1 & 2.71 & 2.63 \\
\hline GISS-E2.1-G & -1.46 & -1.2 & 0.26 & 2.74 & 2.87 \\
\hline GISS-E2.1-H & -1.26 & -1.08 & 0.17 & 2.95 & 3.15 \\
\hline HadGEM3-GC31-LL & -0.82 & -0.58 & 0.24 & 4.72 & 5.73 \\
\hline INM-CM4.8 & -1.8 & -0.98 & 0.82 & 1.74 & 1.91 \\
\hline INM-CM5.0 & -1.7 & -1.09 & 0.6 & 1.85 & 2.02 \\
\hline IPSL-CM6A-LR & -1.01 & -0.65 & 0.36 & 3.86 & 4.76 \\
\hline MIROC-ES2L & -1.48 & -1.94 & -0.46 & 2.69 & 2.53 \\
\hline MIROC6 & -1.63 & -1.44 & 0.19 & 2.4 & 2.59 \\
\hline MPI-ESM1.2-HR & -1.51 & -0.81 & 0.7 & 2.77 & 3.34 \\
\hline MRI-ESM2.0 & -1.45 & -0.85 & 0.6 & 2.75 & 3.41 \\
\hline NESM3 & -0.94 & -0.79 & 0.15 & 4.27 & 4.72 \\
\hline NorESM2-LM & -2.06 & -0.83 & 1.23 & 2.24 & 2.98 \\
\hline SAM0-UNICON & -1.16 & -0.74 & 0.42 & 3.6 & 4.19 \\
\hline UKESM1.0-LL & -0.79 & -0.63 & 0.17 & 4.84 & 5.49 \\
\hline Mean (median) & $-1.24(-1.19)$ & $-0.84(-0.74)$ & $0.4(0.42)$ & $3.4(3.07)$ & $4.08(4.4)$ \\
\hline Standard deviation & 0.37 & 0.38 & 0.34 & 1.01 & 1.27 \\
\hline
\end{tabular}

Following Armour (2017) and Andrews et al. (2018), we rewrite Eq. (2) as

$$
\mathrm{ECS}=-\frac{F_{2 \times}}{\lambda_{\text {eq }}}=-\frac{F_{2 \times}}{\lambda_{\text {hist }}+\lambda^{\prime}},
$$

where $\lambda_{\text {hist }}$ is the feedback parameter estimated from historical energy budget constraints, and $\lambda^{\prime}$ is the change in feedback at the equilibrium state relative to the historical period. Using $\lambda_{\text {hist }}$ based on historical energy budgets, one can make an estimate of climate sensitivity (termed $\mathrm{ECS}_{\text {hist }}$ herein):

$$
\mathrm{ECS}_{\text {hist }}=-\frac{F_{2 \times}}{\lambda_{\text {hist }}}
$$

which will underestimate the value of ECS if $\lambda^{\prime}>0$. Note that while $\lambda^{\prime}$ is expected to have the same sign of $\Delta \lambda$ (positive in most GCMs), their magnitudes will be smaller. The change $\Delta \lambda$ is defined as the change in feedbacks between the first 20 years and the last 130 years of abrupt $4 \times \mathrm{CO} 2$ simulations, whereas $\lambda^{\prime}$ is defined in terms of how feedbacks will change from historical warming to equilibrium warming under $\mathrm{CO}_{2}$ forcing. Armour (2017, hereafter A17) and Lewis and Curry (2018, hereafter LC18) proposed a ratio of ECS to

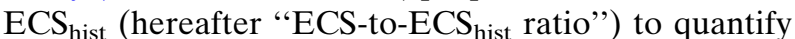
the difference in ECS estimates, and reported the

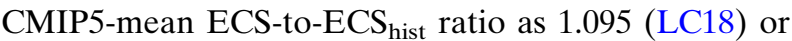
1.26 (A17). The difference between these estimates is attributed to the differences in the method and time scale of regression used and to differences in assumptions about how $\mathrm{CO}_{2}$ forcing scales with $\mathrm{CO}_{2}$ concentration (LC18).

Ideally, estimates of $\lambda_{\text {hist }}$ and ECS $S_{\text {hist }}$ require accurate estimates of historical energy budgets from observations or GCM simulations with all historical forcing agents included (e.g., historical simulations). In the latter case, 
TABLE 3. As in Table 2, but for the CMIP5 models.

\begin{tabular}{|c|c|c|c|c|c|}
\hline CMIP5 model & $\lambda_{1-20}$ & $\lambda_{21-150}$ & $\Delta \lambda$ & $\mathrm{ECS}_{1-20}$ & $\mathrm{ECS}_{21-150}$ \\
\hline ACCESS1.0 & -1.15 & -0.57 & 0.57 & 3.1 & 4.3 \\
\hline ACCESS1.3 & -1.17 & -0.5 & 0.67 & 2.92 & 4.36 \\
\hline BCC-CSM1.1 & -1.49 & -0.87 & 0.62 & 2.54 & 3 \\
\hline BCC-CSM1.1-m & -1.42 & -0.91 & 0.51 & 2.71 & 3.05 \\
\hline CanESM2 & -1.23 & -0.89 & 0.33 & 3.4 & 3.85 \\
\hline CCSM4 & -1.57 & -0.89 & 0.69 & 2.6 & 3.2 \\
\hline CNRM-CM5 & -1.06 & -1.24 & -0.19 & 3.38 & 3.18 \\
\hline CSIRO-Mk3.6.0 & -1.25 & -0.4 & 0.85 & 2.84 & 5.03 \\
\hline GFDL CM3 & -1.19 & -0.61 & 0.58 & 3.11 & 4.3 \\
\hline GFDL-ESM2G & -1.51 & -0.64 & 0.87 & 2.32 & 3.02 \\
\hline GFDL-ESM2M & -1.48 & -0.99 & 0.49 & 2.42 & 2.68 \\
\hline GISS-E2-H & -1.86 & -1.4 & 0.46 & 2.21 & 2.39 \\
\hline GISS-E2-R & -2.47 & -1.3 & 1.17 & 1.88 & 2.31 \\
\hline HadGEM2-ES & -0.83 & -0.34 & 0.49 & 4.01 & 6.02 \\
\hline INM-CM4 & -1.5 & -1.26 & 0.23 & 2.04 & 2.16 \\
\hline IPSL-CM5A-LR & -0.89 & -0.62 & 0.27 & 3.77 & 4.44 \\
\hline IPSL-CM5A-MR & -0.91 & -0.62 & 0.29 & 3.85 & 4.52 \\
\hline IPSL-CM5B-LR & -1.29 & -0.79 & 0.5 & 2.35 & 2.79 \\
\hline MIROC5 & -1.66 & -1.3 & 0.36 & 2.64 & 2.84 \\
\hline MPI-ESM-LR & -1.38 & -0.87 & 0.51 & 3.32 & 3.89 \\
\hline MPI-ESM-MR & -1.48 & -0.88 & 0.59 & 3.16 & 3.73 \\
\hline MPI-ESM-P & -1.57 & -0.96 & 0.61 & 3.13 & 3.68 \\
\hline MRI-CGCM3 & -1.56 & -1.13 & 0.43 & 2.31 & 2.66 \\
\hline NorESM1-M & -1.61 & -0.77 & 0.85 & 2.34 & 3.18 \\
\hline Mean (median) & $-1.40(-1.45)$ & $-0.86(-0.88)$ & $0.53(0.51)$ & $2.85(2.78)$ & $3.52(3.19)$ \\
\hline Standard deviation & 0.35 & 0.3 & 0.27 & 0.58 & 0.95 \\
\hline
\end{tabular}

additional simulations with the same historical forcings but fixed SSTs are needed to diagnose the magnitude of forcing, namely, the Radiative Forcing Model Intercomparion Project (RFMIP; Pincus et al. 2016). Given the absence of the RFMIP simulations for the majority of the current CMIP5 and CMIP6 models, several ways to approximate $\mathrm{ECS}_{\text {hist }}$ are proposed, for example, using abrupt $4 \times \mathrm{CO} 2$ or 1 pctCO 2 simulations as an analog for historical warming (A17, LC18), or estimating historical forcings based on empirical scaling (Gregory et al. 2020). Here, following LC18, we make use of the early portion of abrupt $4 \times \mathrm{CO} 2$ simulations as a historical analog to estimate ECS $_{\text {hist }}$ by regressing $N$ against $T$ over years $2-50$ of each model's abrupt $4 \times \mathrm{CO} 2$ simulation. We also calculate $F_{2 \times}$ by scaling the $y$-axis intercept of the regression of $N$ against $T$ over years $2-10$. Long-term ECS here is estimated from the regression of $N$ against $T$ over years $21-150$ (equal to $\mathrm{ECS}_{21-150}$ ), which is the same period used in both A17 and LC18, but using Deming regression to be consistent with LC18 for comparison. We also provide the results using a more conventional estimate of ECS derived from the $N-T$ regression over years $1-150\left(\mathrm{ECS}_{1-150}\right.$; shown in parentheses in Table 4).

The results of individual CMIP6 models and ensemble means are shown in Table 4. The pattern-effect induced feedback evolution from the historical period to equilibrium $\left(\lambda^{\prime}\right)$ is on average weaker in CMIP6 models $\left(0.06 \mathrm{~W} \mathrm{~m}^{-2} \mathrm{~K}^{-1}\right)$ relative to CMIP5 models $\left(0.092 \mathrm{~W} \mathrm{~m}^{-2} \mathrm{~K}^{-1}\right)$, so that the ECS-to-ECS $\mathrm{Eist}_{\text {r }}$ ratio is also reduced in the CMIP6 ensemble mean $(6 \%)$ compared to the CMIP5 ensemble mean $(9.5 \%$; consistent with LC18). This suggests that the latest generation of GCMs produce an overall smaller ECS-to-ECS hist $_{\text {ratio, }}$ consistent with results above that the pattern effect is slightly smaller in the abrupt $4 \times \mathrm{CO} 2$ simulations. However, there remains a large spread across CMIP6 models: $\lambda^{\prime}$ varies from 0.3 to $-0.23 \mathrm{~W} \mathrm{~m}^{-2} \mathrm{~K}^{-1}$, corresponding to ECS values that are $40 \%$ higher to $12 \%$ lower than $\mathrm{ECS}_{\text {hist. }}$.

We note an important caveat of this analysis regarding the calculation of $\mathrm{ECS}_{\text {hist }}$. Making use of abrupt $4 \times \mathrm{CO} 2$ simulations as an analog for the historical energy budget is a useful approach as it enables intermodel comparison, but it may produce different values of $\mathrm{ECS}_{\text {hist }}$ than those estimated from historical simulations that include a more realistic time evolution of $\mathrm{CO}_{2}$ and non- $\mathrm{CO}_{2}$ forcings as well as an unforced pattern effect (Marvel et al. 2016: Gregory et al. 2020; Andrews et al. 2019). For example, Andrews et al. (2019) found that ECS hist within historical simulations of HadGEM3-GC3.1-LL is $4.7 \mathrm{~K}$, with a ECS-to-ECS ${ }_{\text {hist }}$ ratio of 1.21. For comparison, using 


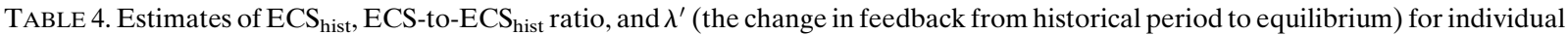
CMIP6 models and ensemble means of CMIP5 and CMIP6, to be compared with Table S2 in Lewis and Curry (2018). For ECS-to-ECS hist ratio and $\lambda^{\prime}$, the results shown are calculated with the values of effective ECS derived from regressions over years 21-150 (or years 1-150), using the Deming regression method.

\begin{tabular}{|c|c|c|c|}
\hline CMIP6 model & $\mathrm{ECS}_{\text {hist }}$ & $\begin{array}{c}\text { ECS-to-ECS } \\
\qquad \begin{array}{c}\text { hist } \\
\text { ratio years } 21-150)\end{array}\end{array}$ & $\lambda^{\prime}$ years $21-150($ years $1-150)$ \\
\hline ACCESS-CM2 & 4.05 & $1.28(1.13)$ & $0.22(0.12)$ \\
\hline ACCESS-ESM1.5 & 3.13 & $1.41(1.19)$ & $0.31(0.17)$ \\
\hline BCC-CSM2-MR & 2.81 & $1.06(1.04)$ & $0.06(0.05)$ \\
\hline BCC-ESM1 & 3.05 & $1.07(1.05)$ & $0.07(0.05)$ \\
\hline CAMS-CSM1.0 & 2.19 & $0.98(1.02)$ & $-0.04(0.03)$ \\
\hline CESM2 & 4.16 & $1.4(1.21)$ & $0.32(0.2)$ \\
\hline CESM2-WACCM & 3.9 & $1.32(1.17)$ & $0.25(0.15)$ \\
\hline CNRM-CM6.1 & 4.72 & $0.96(1.02)$ & $-0.03(0.02)$ \\
\hline CNRM-ESM2.1 & 4.52 & $0.91(1.02)$ & $-0.06(0.01)$ \\
\hline CanESM5 & 5.33 & $1.05(1.04)$ & $0.03(0.03)$ \\
\hline E3SM-1.0 & 4.91 & $1.1(1.07)$ & $0.06(0.04)$ \\
\hline EC-Earth3 & 3.87 & $1.09(1.1)$ & $0.08(0.09)$ \\
\hline EC-Earth3-Veg & 3.91 & $1.08(1.09)$ & $0.07(0.08)$ \\
\hline GFDL-CM4 & 3.16 & $1.12(1.14)$ & $0.13(0.16)$ \\
\hline GFDL-ESM4 & 2.55 & $0.88(0.98)$ & $-0.2(-0.02)$ \\
\hline GISS-E2.1-G & 2.57 & $1(1.03)$ & $0(0.04)$ \\
\hline GISS-E2.1-H & 2.95 & $0.99(1.02)$ & $-0.01(0.03)$ \\
\hline HadGEM3-GC31-LL & 5.24 & $1.08(1.05)$ & $0.06(0.04)$ \\
\hline INM-CM4.8 & 1.74 & $1.05(1.04)$ & $0.09(0.07)$ \\
\hline INM-CM5.0 & 1.84 & $1(1.02)$ & $0(0.04)$ \\
\hline IPSL-CM6A-LR & 4.31 & $1.01(1.02)$ & $0.01(0.02)$ \\
\hline MIROC-ES2L & 2.62 & $0.88(1.02)$ & $-0.23(-0.04)$ \\
\hline MIROC6 & 2.37 & $0.95(1.03)$ & $-0.09(0.05)$ \\
\hline MPI-ESM1.2-HR & 2.63 & $1.18(1.11)$ & $0.23(0.15)$ \\
\hline MRI-ESM2.0 & 2.68 & $1.09(1.11)$ & $0.11(0.13)$ \\
\hline NESM3 & 4.78 & $0.91(0.96)$ & $-0.08(-0.04)$ \\
\hline NorESM2-LM & 1.88 & $1.1(1.16)$ & $0.22(0.34)$ \\
\hline SAM0-UNICON & 3.38 & $1.05(1.06)$ & $0.06(0.06)$ \\
\hline UKESM1.0-LL & 5.12 & $1.06(1.04)$ & $0.05(0.03)$ \\
\hline CMIP6 mean & 3.46 & $1.07(1.07)$ & $0.06(0.07)$ \\
\hline CMIP6 std & 1.08 & $0.13(0.06)$ & $0.13(0.08)$ \\
\hline CMIP5 mean & 2.807 & $1.095(1.073)$ & $0.092(0.086)$ \\
\hline CMIP5 std & 0.59 & $0.134(0.063)$ & $0.141(0.069)$ \\
\hline
\end{tabular}

HadGEM3-GC3.1-LL's abrupt $4 \times \mathrm{CO} 2$ simulation, our calculation gives an $\mathrm{ECS}_{\text {hist }}$ of $5.2 \mathrm{~K}$, and an ECS-to$\mathrm{ECS}_{\text {hist }}$ ratio of 1.08 (Table 4), suggesting that the values reported here may underestimate the historical pattern effect. However, our main focus is to provide information on the difference in pattern effect between the CMIP5 and CMIP6 ensembles, rather than to provide a definitive ECS $_{\text {hist }}$ metric for each model. Future work employing RFMIP simulations to accurately quantify radiative feedbacks in the historical simulations of CMIP6 models is needed to shed light on this in greater detail.

\section{The consistency and difference in ensemble- mean $\Delta \lambda$ between CMIP5 and CMIP6}

Even though $\Delta \lambda$ does not contribute as much as $\lambda_{1-20}$ to the intermodel spread in ECS, it substantially affects
ECS estimates for both CMIP5-mean and CMIP6-mean projections (comparing $\mathrm{ECS}_{1-20}$ to $\mathrm{ECS}_{21-150}$ in Figs. 1e and 1f). In this section, we first compare the global-mean $\Delta \lambda$ and its individual components partitioned by radiative kernels. We then examine the spatial patterns of ensemble-mean $\Delta \lambda$ from CMIP5 and CMIP6 models. A comparison of SST patterns is also provided to aid in uncovering the causes of ensemble differences.

Figure 2 shows global-mean net $\Delta \lambda$ and its individual components associated with changes in atmospheric temperature, water vapor, lapse rate, surface albedo, and clouds, estimated using radiative kernels (Huang et al. 2017) as described in Zelinka et al. (2020). We calculate the cloud feedback using radiative kernels by removing cloud masking effects from the temperaturemediated change in net cloud radiative effect. An overall consistency between CMIP5 and CMIP6 is found in the 


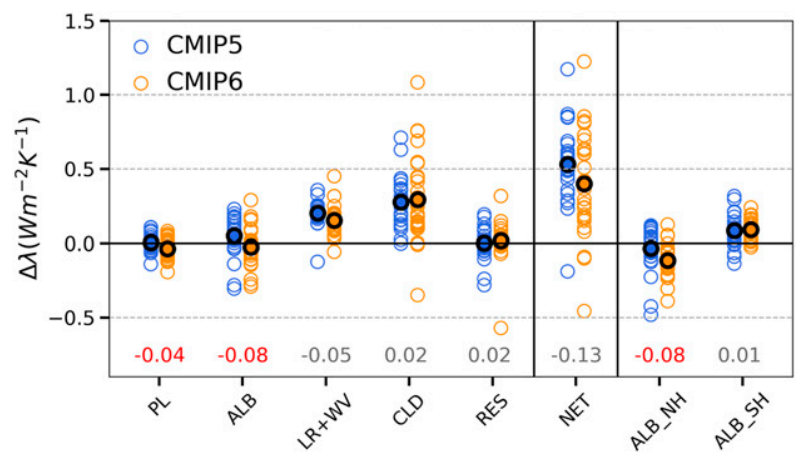

FIG. 2. The $\Delta \lambda$ for each individual CMIP5 models (blue circles), CMIP6 models (orange circles), and their multimodel means (black circles), decomposed into contributions of (from left to right) Planck (PL), surface albedo (ALB), the sum of lapse rate (LR) and water vapor (WV), net cloud (CLD), and residual (RES), respectively. The $\Delta \lambda_{\mathrm{ALB}}$ is further broken down into contributions from Northern Hemisphere (ALB_NH) and Southern Hemisphere (ALB_SH). The differences between CMIP5 means and CMIP6 means are printed at the bottom, with red numbers highlighting multimodel means that are significantly different $(p<0.05)$.

fact that the dominant contribution to the ensemblemean $\Delta \lambda$ comes from the net cloud component $\left(\Delta \lambda_{\mathrm{CLD}}\right)$, followed by the sum of lapse rate $\left(\Delta \lambda_{\mathrm{LR}}\right)$ and water vapor $\left(\Delta \lambda_{\mathrm{WV}}\right)$ components. Both CMIP5 and CMIP6 have a large spread in the net $\Delta \lambda$, primarily owing to the spread in $\Delta \lambda_{\text {CLD }}$. However, the (positive) ensemblemean net $\Delta \lambda$ is slightly smaller in CMIP6, primarily due to a smaller surface-albedo feedback change $\left(\Delta \lambda_{\mathrm{ALB}}\right)$, particularly from the Northern Hemisphere $(\mathrm{NH})$.

We next show the spatial patterns of ensemble-mean feedbacks for the CMIP5 and CMIP6 models (Figs. 3 and 4). The feedback patterns are first calculated for each model by regressing the corresponding local $N$ against global-mean $T$ over the two separate time periods, and then averaging across models. The patterns of local contributions to the net feedback change are qualitatively consistent between the two ensemble means (Figs. 3 and 4, first row). That is, the positive changes in the net feedback primarily come from the tropical eastern Pacific. This is a region where a cool ocean and a strong capping inversion promote ubiquitous low clouds in the climatology. Because warmer surface temperatures and weaker low-level stability in this region both reduce low cloud cover, delayed warming in this region will yield a less-negative feedback during the approach toward equilibrium (Zhou et al. 2016; Ceppi and Gregory 2017). Indeed, among all individual components, cloud feedback and lapse-rate feedback contribute the most to the positive change in the net feedback over this region in both CMIP5 and CMIP6. The major difference between the two ensembles lies in the Arctic, where positive surface-albedo feedback strengthens with time in the
CMIP5 models (Fig. 3, bottom row) but weakens over time in the CMIP6 models (Fig. 4, bottom row), consistent with the regional attribution results in Fig. 2.

Changes in the strength of the surface-albedo feedback may arise from changes in the sensitivity of local albedo to local surface temperature (a nonlinear state dependence; e.g., Goosse et al. 2018), or from differences in surface warming patterns acting on constant local surface-albedo feedbacks (e.g., Armour et al. 2013), or from a combination of these two factors. The state dependence can be identified through changes in the local surface-albedo feedback, which is defined by regressing local $N$ onto local $T$ (rather than global $T$ ), assuming that the local surface-albedo feedback is independent of the pattern of surface warming. We found that the local surface-albedo feedback over the Arctic slightly strengthens over time in both ensembles, indicating a nonlinear state dependence, but that the change in local surface-albedo feedback from fast to slow time scale is nearly identical in the CMIP5 and CMIP6 multimodel means. Moreover, while this nonlinear state dependence-induced strengthening of the local surfacealbedo feedback over time may enhance the strengthening of the Arctic surface-albedo feedback within CMIP5 (Fig. 3, bottom row), it opposes to the weakening of the Arctic surface-albedo feedback within CMIP6 (Fig. 4, bottom row), suggesting that $\Delta \lambda_{\mathrm{ALB}}$ is primarily governed by changing warming patterns rather than by local state dependence. Indeed, the relative warming in the Arctic over the first 20 years is stronger in CMIP6 than CMIP5 (Fig. 5c), but it becomes weaker over the following decades in CMIP6 relative to CMIP5 (Fig. 5f). As a result of this change in the rate of Arctic warming, the Arctic surface-albedo feedback on average weakens over time (i.e., negative $\Delta \lambda_{\mathrm{ALB}}$ ) within CMIP6 models (Fig. 4), which overcomes the positive $\Delta \lambda_{\mathrm{ALB}}$ arising from enhanced warming of the Southern Ocean on the slow time scale (Fig. 4 bottom row), leading to a slightly negative value of global-mean $\Delta \lambda_{\mathrm{ALB}}$ and an overall smaller value of global-mean $\Delta \lambda$ in CMIP6 models (Fig. 2).

\section{The source of the intermodel spread in $\Delta \lambda$ across CMIP5 and CMIP6}

We next move away from the multimodel mean perspective, to consider why individual models have different values of $\Delta \lambda$. We find it conceptually helpful to consider that radiative feedbacks and their changes may be influenced by both atmospheric model physics and SST patterns. To separate the two factors, we make use of radiative feedback "Green's functions" (Zhou et al. 2017; Dong et al. 2019), which will be introduced in 


\section{CMIP5}
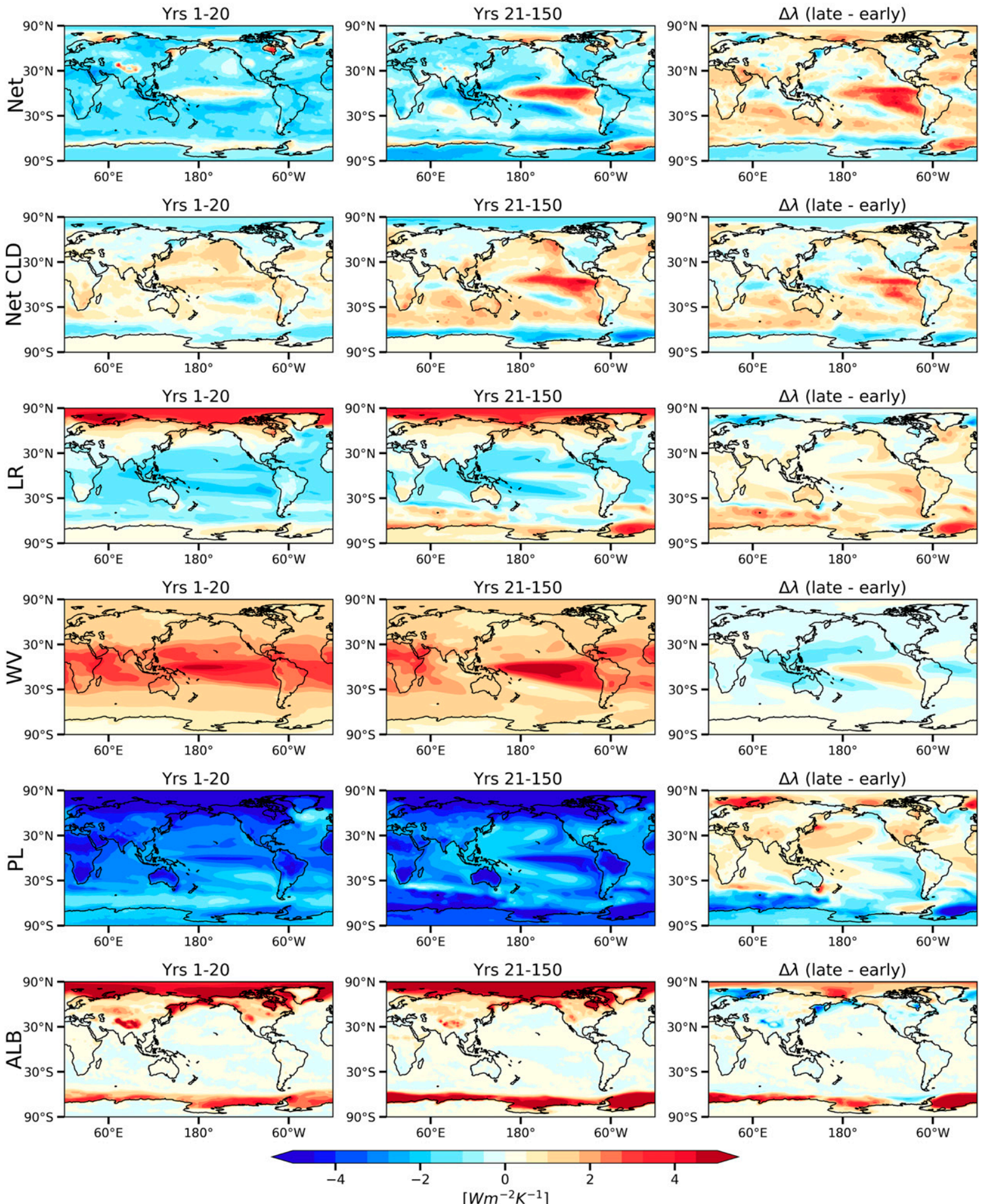

FIG. 3. CMIP5 ensemble-mean spatial patterns of the local radiative feedback components (calculated by regressing the local $N$ against global-mean T). Shown from top to bottom are net feedback, net cloud feedback, lapse-rate feedback, water-vapor feedback, Planck feedback, and surface-albedo feedback, on time scales of (left) years 1-20 and (center) years 21-150, and (right) the change (late minus early). 


\section{CMIP6}
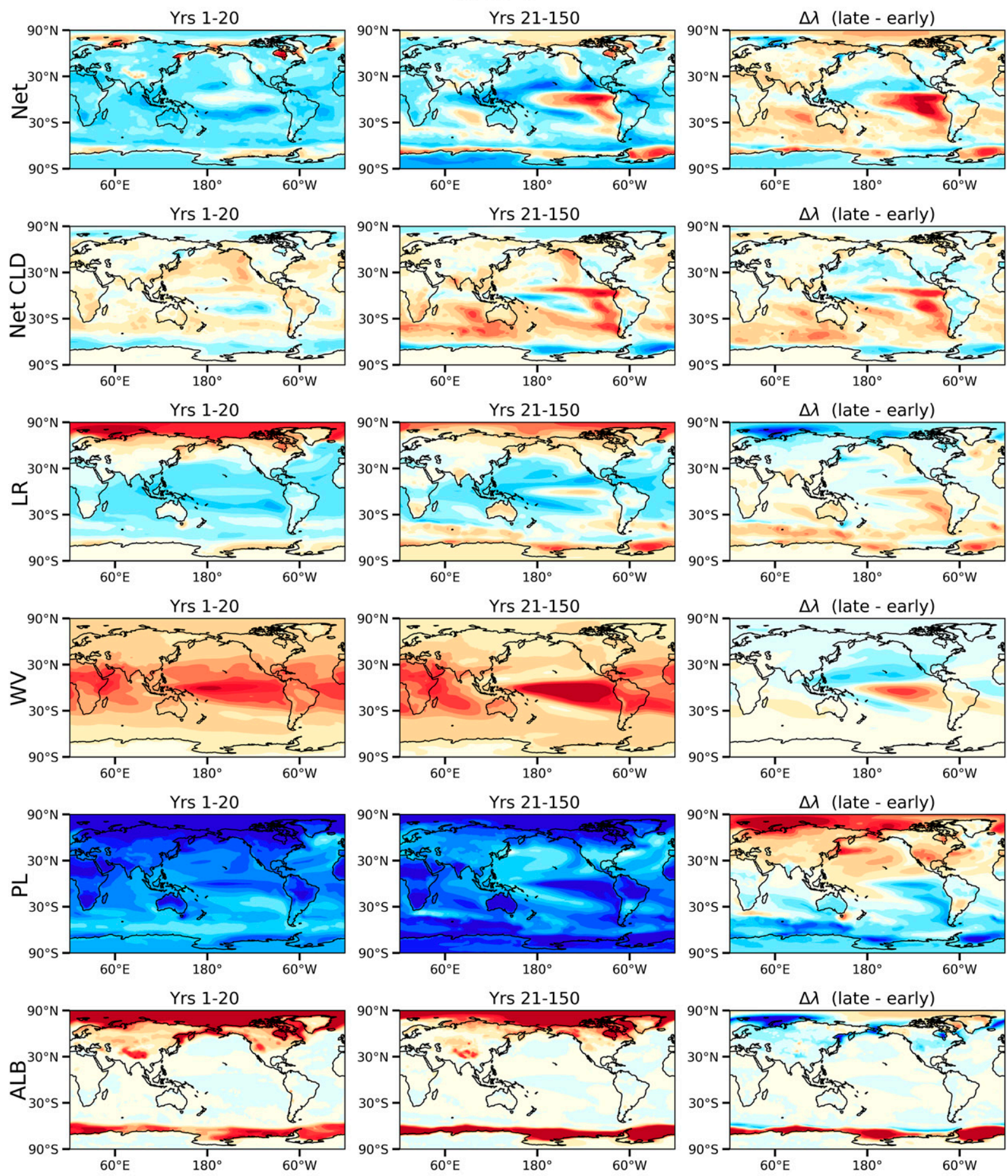

$\left[W m^{-2} K^{-1}\right]$

FIG. 4. As in Fig. 3, but for CMIP6 ensemble means. 


\section{CMIP5}

a.

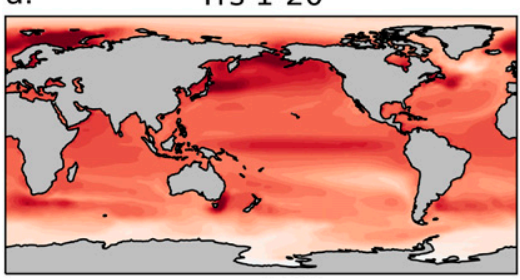

d.

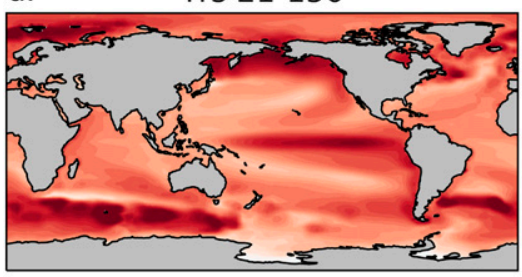

g. Change (late - early)

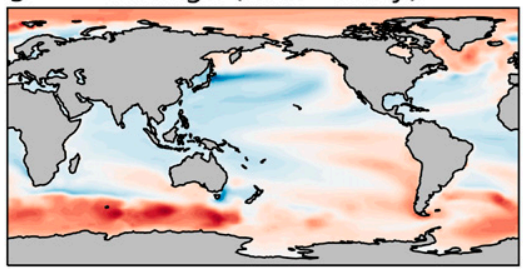

CMIP6
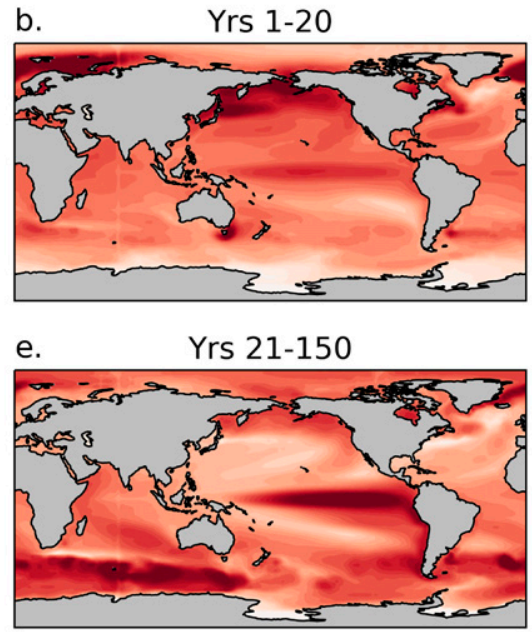

h. Change (late - early)

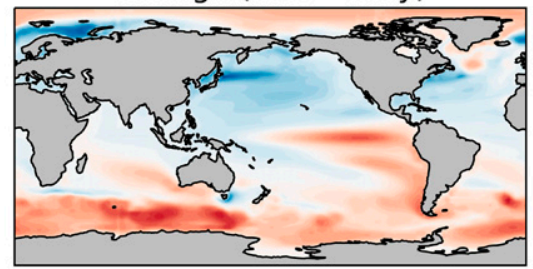

Difference(6-5)
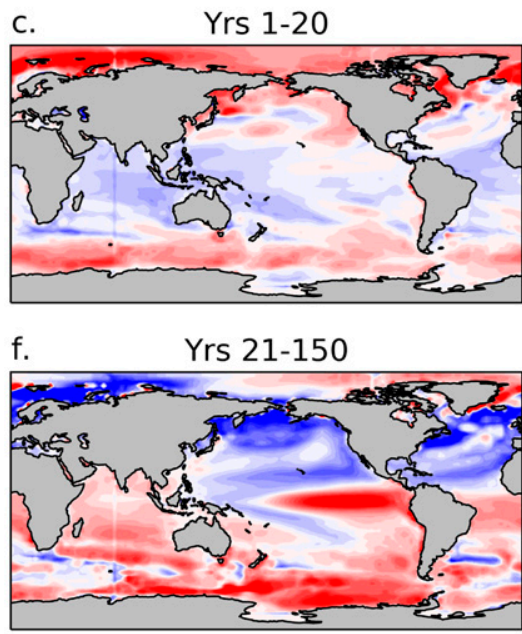

i. Change (late - early)
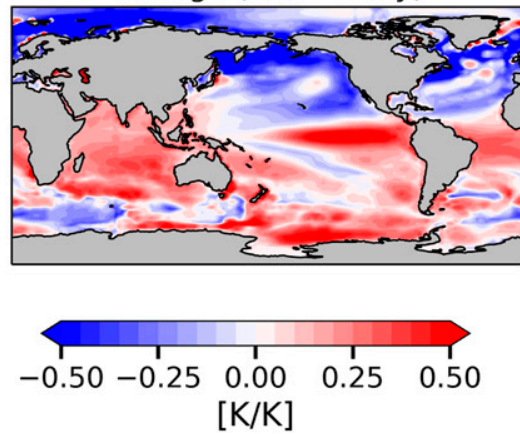

FIG. 5. Spatial patterns of SST changes (SST*) over (top) years 1-20 and (middle) years 21-150, and (bottom) their changes (late minus early), for (a)-(c) CMIP5 multimodel mean, (d)-(f) CMIP6 multimodel mean, and (g)-(i) the difference (CMIP6 minus CMIP5). The values of SST* are calculated as the regression slope of local SST changes against global-mean SST changes, such that the global mean of (a), (b), (d), and (e) is one by construction. Note that the color scales in the left two columns and in the right column are different.

section $4 \mathrm{a}$. In sections $4 \mathrm{~b}$ and $4 \mathrm{c}$, we investigate the major source of the intermodel spread in $\Delta \lambda$ across the CMIP5 and CMIP6 models, respectively.

\section{a. Green's functions}

To separate the effect of SST patterns and the effect of model physics, we use radiative feedback Green's functions, as they predict the radiative response based solely on SST anomaly patterns, given the atmospheric physics of the parent model from which they were derived. The basis of a Green's function is a Jacobian matrix, representing the sensitivity of any regional response to regional SST anomalies, which consists of both local and nonlocal effects of changes in SST. The full Jacobian is calculated from a series of prescribed-SST simulations within an AGCM, each with a single patch of SST anomalies on the top of climatological SSTs. Then, convolving the Jacobian with a global SST anomaly pattern can predict the global response to the given SST pattern, based on the assumption of spatial linearity, which has been shown to be a good approximation (Zhou et al. 2017; Dong et al. 2019). Hence, applying the Green's functions linearly separates the differences in SST patterns and the differences in the sensitivity of radiative feedbacks on SST patterns.

Here we employ two Green's functions: one derived from the Community Atmosphere Model version 5 (CAM5) by Zhou et al. (2017), and one derived from CAM4 by Dong et al. (2019). The major difference between CAM4 and CAM5 Green's functions lies in the representation of cloud properties within the two models, which are reported to be more realistic in CAM5 (Kay et al. 2012), although both models exhibit large biases in the subtropical marine boundary layer cloud regimes. Throughout this study, we use the two-dimensional global-mean Jacobians (denoted as $\mathcal{J}_{X}$, the sensitivity 
of a global-mean response $X$ to each grid of SST anomalies) for computational efficiency because our focus is on global-mean quantities. To compute feedback parameters from the Green's functions, we first reconstruct annual global-mean net TOA radiative response $R$ and surface air temperature response $T$ by convolving the Green's functions $\mathcal{J}_{X}$ with each model's annual-mean global SST change [SST(r)],

$$
X=\mathcal{J}_{X} \cdot \operatorname{SST}(\mathbf{r})
$$

where $X$ can be any response (e.g., $R, T$ ), and $\operatorname{SST}(\mathbf{r})$ denotes the global pattern of SST anomalies. Then $\lambda_{1-20}$, $\lambda_{21-150}$, and $\Delta \lambda$ are calculated following the same regressions used to process model outputs. Note that the Green's function can only predict the TOA radiative response $R(=\lambda T)$, which is different from the net TOA radiation imbalance $N$ in fully coupled GCMs, because the latter includes the effective radiative forcing of $\mathrm{CO}_{2}$ quadrupling $F_{4 \times}: N=F_{4 \times}+R$. Indeed, the effective radiative forcing also varies slightly across models; but it is abruptly imposed and held constant over time. Therefore, while radiative forcing matters for ECS itself, its absence does not cause any inconsistency in the estimates of feedbacks (defined as the regression slope in Gregory plots) between Green's functions and the GCM simulations.

\section{b. Intermodel spread in $\Delta \lambda$ across CMIP5 models}

We first show the comparison of feedbacks from CMIP5 GCMs and those reconstructed by the CAM4/ CAM5 Green's functions (Fig. 6). Both Green's functions poorly capture $\lambda_{1-20}$ but approximately reproduce GCM values of $\Delta \lambda$, suggesting that $\lambda_{1-20}$ and $\Delta \lambda$ are governed by different processes. The failure of the Green's functions in reconstructing $\lambda_{1-20}$ may come from several factors; for example, the Green's functions fail to account for the radiative response to land warming which emerges generally on fast time scales. However, we favor the interpretation that the spread in $\lambda_{1-20}$ is primarily determined by each model's atmospheric physics (e.g., cloud parameterizations). Therefore, the radiative responses from each model cannot be captured by Green's functions derived from either CAM4 or CAM5, which have distinct atmospheric physics. On the other hand, the fact that both Green's functions more accurately reproduce $\Delta \lambda$, even though they are built from different models, suggests that the spread in $\Delta \lambda$ arises primarily from the changes in SST patterns and is largely insensitive to model physics.

We next investigate what regions of SSTs drive the intermodel spread in $\Delta \lambda$ across the CMIP5 models.
Previous studies have pointed out the importance of tropical warming through changing cloud and lapse-rate feedbacks. Zhou et al. (2016) proposed the role of the tropical eastern Pacific, where relative cooling in recent decades is thought to be responsible for driving an increase in local low cloud and a more-negative cloud feedback. Andrews and Webb (2018) further established a mechanism associated with east-west tropical Pacific SST gradient that governs the change in tropospheric stability, and therefore the change in low clouds and lapse rate. Silvers et al. (2018) highlighted changes in low clouds throughout the tropics beyond the traditional stratocumulus regimes in driving decadal variability of feedbacks over the historical period. Recently, Dong et al. (2019) proposed that $\Delta \lambda$ tracks the ratio of warming in the west Pacific warm-pool (WP) regions relative to warming in the rest of global ocean areas $\gamma$. Here we test this mechanism by examining the correlation of $\Delta \lambda$ against the proposed WP warming ratio change $\Delta \gamma$ across models.

To calculate $\Delta \gamma$ for all CMIP5 and CMIP6 models, we define WP regions in this study as grid cells within $30^{\circ} \mathrm{S}-$ $30^{\circ} \mathrm{N}, 30^{\circ} \mathrm{E}-160^{\circ} \mathrm{W}$ that have an upward vertical velocity at $500 \mathrm{hPa}\left(\omega_{500}\right)$ in the piControl simulation. Unlike the fixed rectangular area in the west Pacific used in Dong et al. (2019), this updated metric takes into account mean-state biases, ensuring that in each model the WP regions capture the radiative responses in regions of deep convection. Note that results using the fixed region in Dong et al. (2019) are similar to those shown here. We also simplify $\gamma$ to be the WP SST warming relative to global-mean surface air temperature changes, calculated as the regression slope of the averaged SST over the selected WP regions against global-mean $T$, over the two time periods used throughout this study (years 1-20 for $\gamma_{1-20}$, years 21-150 for $\gamma_{21-150}$, and $\Delta \gamma=\gamma_{21-150}-$ $\left.\gamma_{1-20}\right)$.

Figure 7a shows that $\Delta \lambda$ is well correlated with $\Delta \gamma$ for CMIP5 models (with $r^{2}=0.63$ ). Although many approximations are made in the derivation (Dong et al. 2019), the simple metric $\Delta \gamma$, which includes no information about radiative response, explains over $60 \%$ of the variance in CMIP5 $\Delta \lambda$. The physical mechanism, as discussed in Dong et al. (2019), is the preeminent impact of WP warming on global TOA radiation change via deep convection. Over the WP regions, where the surface is tightly coupled to the free troposphere by deep convection, surface warming directly enhances upper tropospheric warming. This leads to a stronger negative lapse-rate feedback and a more-negative cloud feedback over low-cloud regions caused by increased lower tropospheric stability, which together promotes a more efficient radiative damping at TOA. On the other hand, 


\section{CMIP5 reconstruction}
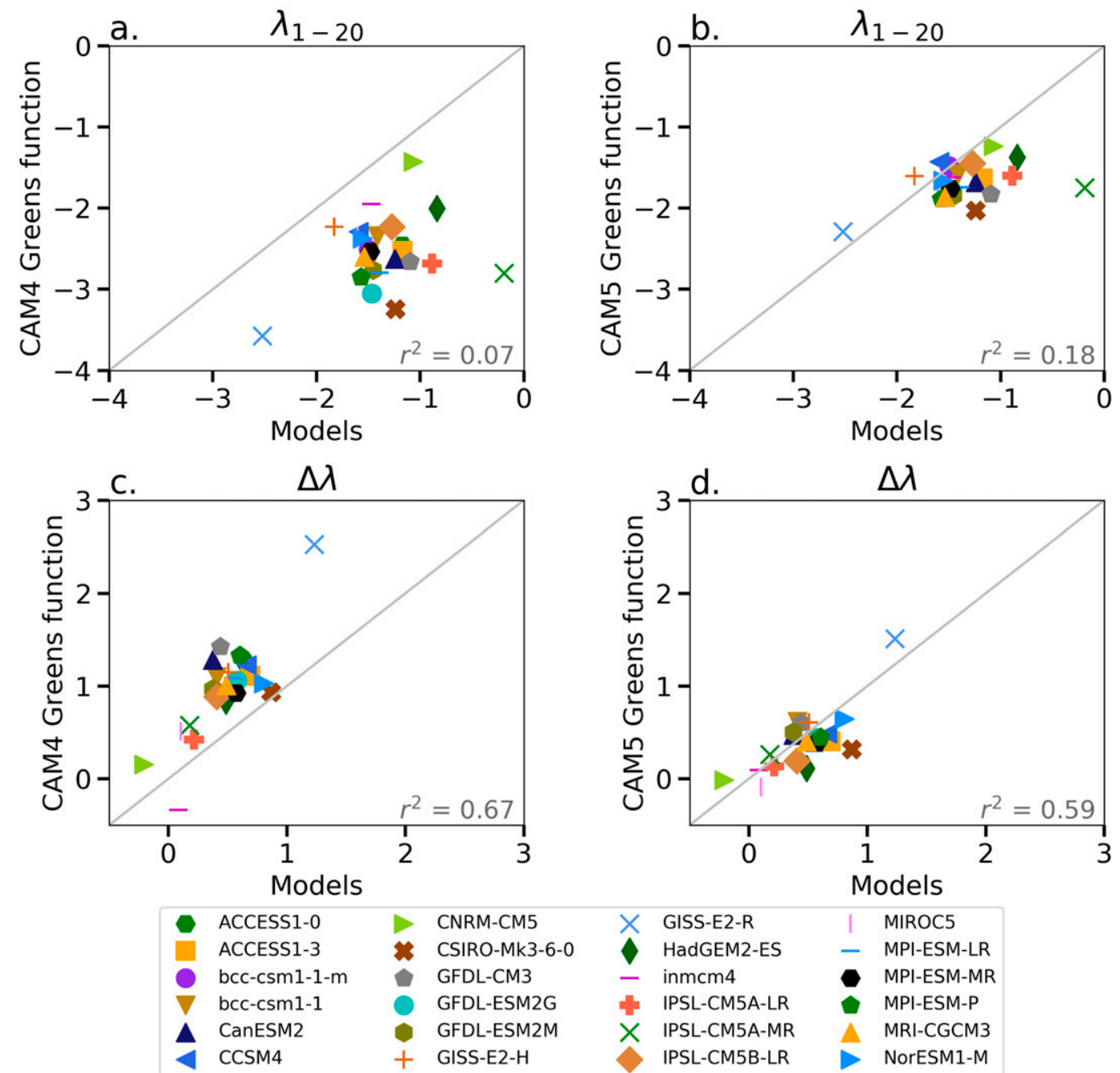

FIG. 6. Comparison of (top) $\lambda_{1-20}$ and (bottom) $\Delta \lambda$ from CMIP5 models and those from the (a),(c) CAM4 and (b),(d) CAM5 Green's function, respectively. Gray lines are the $y=x$ reference line. Variance explained is noted in the bottom-right corner of each panel.

the weaker coupling between surface and upper troposphere in all other regions results in a weak TOA radiation response to surface warming. This leads to a weaker negative lapse-rate feedback, and a more-positive lowcloud feedback, hence, resulting in an inefficient radiative damping (see Dong et al. 2019, their Figs. 4 and 5). The key importance of warm pool warming for TOA radiation changes is also supported by observational evidence (Zhou et al. 2016; Ceppi and Gregory 2017; Fueglistaler 2019).

To further demonstrate the proposed mechanism, we select three representative models that have large positive $\Delta \lambda$ (GISS-E2-R), small positive $\Delta \lambda$ (IPSL-CM5BLR), and small negative $\Delta \lambda$ (CNRM-CM5), respectively.
The term $\Delta \lambda$ is demonstrated as the degree of curvature in the Gregory plots for each model (Figs. 8a-c). We then show their SST warming patterns defined as local SST changes regressed against global-mean SST changes, denoted by SST* (Figs. 8d-1). In this context, values above 1 (in red) indicate local warming exceeding the global-mean warming in the given period, and values below 1 (in blue) indicate local warming weaker than the global-mean warming. In GISS-E2-R, the warm-pool regions warm up relatively quickly during the first 20 years, but warming in the warm pool does not keep pace with warming in other oceans (e.g., the Southern Ocean) over the last 130 years. This sharp transition of surface warming from tropical ascent regions to all other regions 

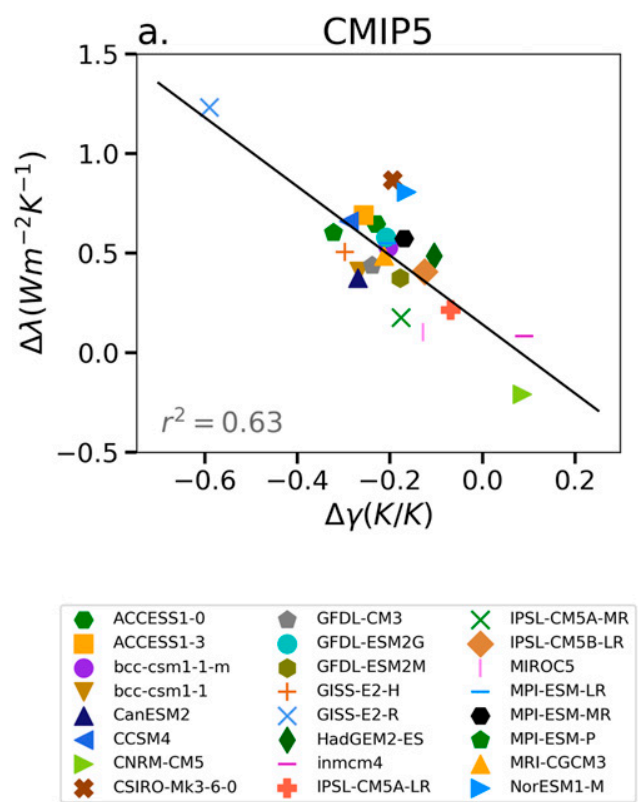

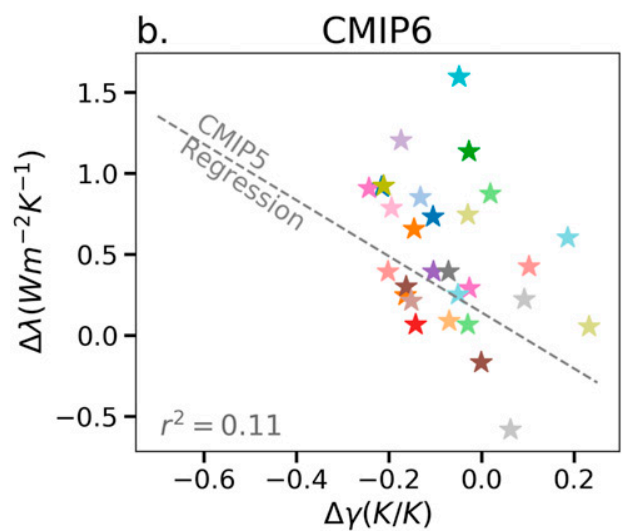

\begin{tabular}{|c|c|c|c|c|c|}
\hline 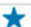 & ACCESS-CM2 & + & E3SM-1-0 & $\star$ & IPSL-CM6A-LR \\
\hline & ACCESS-ESM1-5 & $\Uparrow$ & EC-Earth3 & 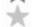 & MIROC-ES2L \\
\hline & BCC-CSM2-MR & $\star$ & EC-Earth3-Veg & + & MIROC6 \\
\hline & BCC-ESM1 & 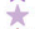 & GFDL-CM4 & 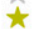 & MPI-ESM1-2-HR \\
\hline & CAMS-CSM1-0 & $\star$ & GFDL-ESM4 & t & MRI-ESM2-0 \\
\hline & CanESM5 & $\AA$ & GISS-E2-1-G & 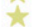 & NESM3 \\
\hline & CESM2 & $\star$ & GISS-E2-1-H & $\star$ & NorESM2-LM \\
\hline & CESM2-WACCM & $\star$ & HadGEM3-GC31-LL & $\star$ & SAMO-UNICON \\
\hline & CNRM-CM6-1 & 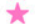 & INM-CM4-8 & + & UKESM1-0-LL \\
\hline & CNRM-ESM2-1 & t & INM-CM5-0 & & \\
\hline
\end{tabular}

FIG. 7. The relation between the change in net feedback $(\Delta \lambda)$ and the change in the west Pacific warm-pool warming ratio $(\Delta \gamma)$, for (a) CMIP5 models and (b) CMIP6 models. The linear fit for CMIP5 models is plotted as the black line in (a) and the gray dashed line in (b). Variance explained is noted in the bottom-left corner of each panel.

is responsible for the large $\Delta \lambda$. In IPSL-CM5B-LR, the WP region does not warm substantially faster than the global average warming on the fast time scale, so that the change in the relative warming over WP regions is weaker, leading to a smaller $\Delta \lambda$. In CNRM-CM5, the WP region warms relatively fast on the longer time scales, leading to a nearly zero change in WP region in contrast to the other two models, driving a negative $\Delta \lambda$. This comparison shows that the CMIP5 values of $\Delta \lambda$ can be well characterized by the ratio of warm-pool to global-mean warming (Fig. 7a), suggesting an important role of tropical convective regions in modulating the strength of radiative feedbacks in CMIP5.

\section{c. Intermodel spread in $\Delta \lambda$ across CMIP6 models}

For CMIP6 models, we first repeat the analysis applying the WP warming ratio. Interestingly, the above theory does not seem to hold as well for CMIP6 models (Fig. 7b), suggesting that the $\Delta \lambda$ spread in the latest models may not directly trace to relative warm-pool warming. One may ask whether this is because the deep convection in other regions (e.g., Atlantic Ocean warmpool regions) carry more weight in the CMIP6 ensemble. To identify the key regions for driving feedback changes, we regress global-mean $\Delta \lambda$ onto local $\Delta$ SST* (the change in the relative warming rate from fast to slow time scale) across CMIP5 and CMIP6 models, respectively, and evaluate the local correlation coefficient $(r)$. Note that SST* is calculated as the local SST change relative to global-mean SST change, and $\Delta$ is defined as the late period (years 21-150) minus the early period (years 1-20).

The resulting correlation maps $(r)$ are shown in Fig. 9. The positive correlation indicates that models that have stronger positive global-mean $\Delta \lambda$ tend to show a locally delayed warming as approaching to equilibrium, whereas the negative correlation indicates that models that have stronger positive global-mean $\Delta \lambda$ tend to show a local warming predominately on the fast time scale. The magnitude of correlation coefficient illustrates the degree to which the intermodel spread in $\Delta \lambda$ correlates with the differences in local warming rates. For example, Fig. 9a shows a strong negative correlation over IndoPacific deep convective regions, which indicates that in the CMIP5 models, $\Delta \lambda$ is primarily governed by the difference in the relative warming in the west Pacific warm-pool regions where greater warming on the fast time scale gives rise to a stronger positive $\Delta \lambda$. This is achieved mostly through $\Delta \lambda_{\mathrm{CLD}}$ (Fig. 9c) and $\Delta \lambda_{\mathrm{LR}}$ (Fig. 9g). However, the results from the CMIP6 models highlight the tropical Indian Ocean, the equatorial eastern Pacific, and the SH midlatitudes (Fig. 9b), which are mostly reflected in the pattern of $\Delta \lambda_{\mathrm{CLD}}$ (Fig. 9d). This comparison suggests that the CMIP5 values of $\Delta \lambda$ may be primarily dominated by surface warming in the broad tropical convective regions, whereas the CMIP6 values of $\Delta \lambda$ may be influenced more by surface warming in the tropical subsidence regions and extratropics. 

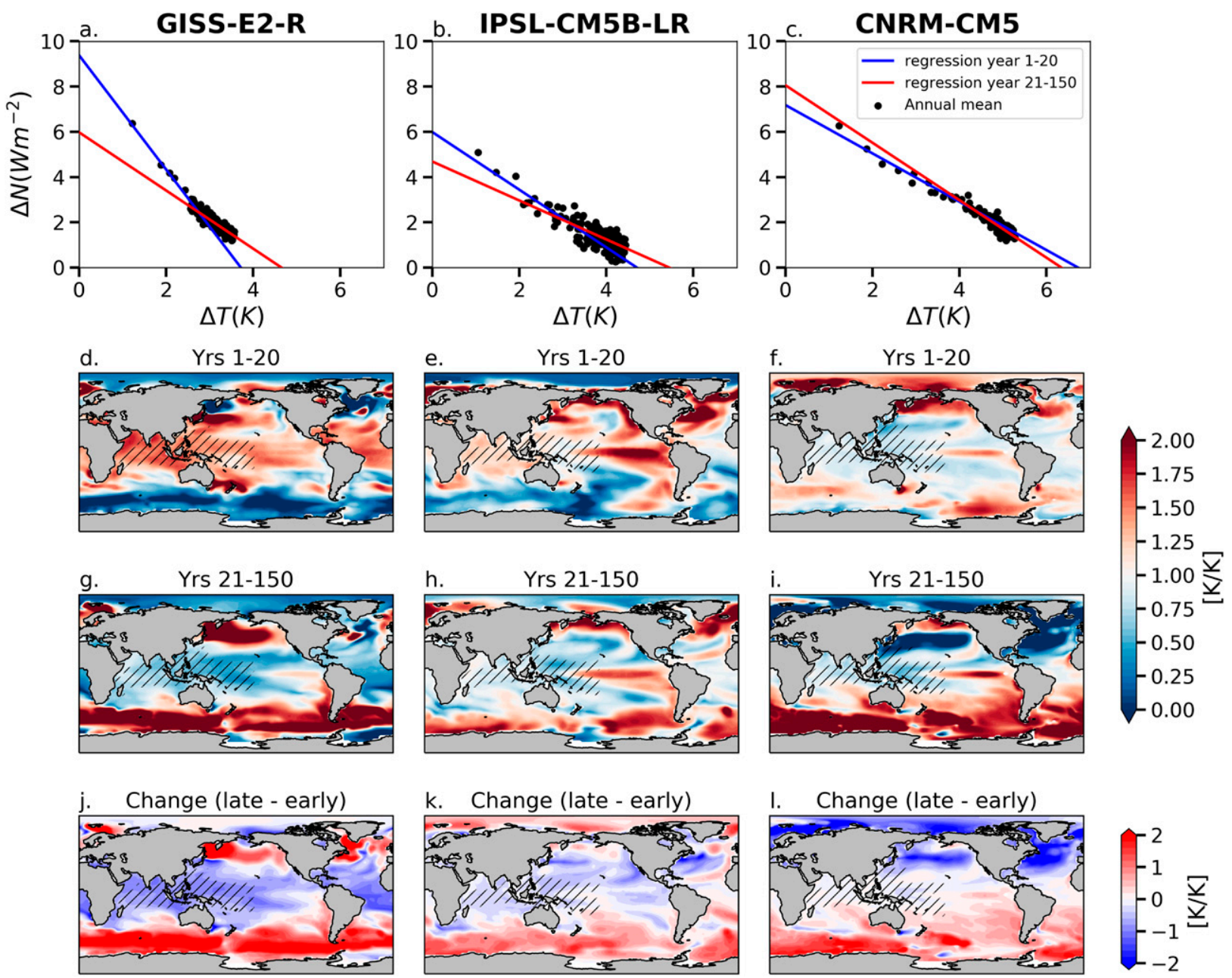

FIG. 8. (a)-(c) Gregory plots and (d)-(1) patterns of SST changes for (left) GISS-E2-R, (center) IPSL-CM5B-LR, and (right) CNRMCM5. Colored lines in (a)-(c) show regression fits for years 1-20 (blue) and for years 21-150 (red). Also shown are the regression slopes of local SST changes against global-mean SST changes over years 1-20 in (d)-(f) and years 21-150 in (g)-(i), and the change between the two time periods (later minus early) in (j)-(l). The hatchings highlight the warm-pool ascent regions in each model.

Indeed, we found that about half of the variance in $\Delta \lambda$ in CMIP5 ensemble can be explained by the change in the estimated inversion strength (EIS) per unit of global warming, whereas the variance in $\Delta \lambda$ explained by the EIS change in CMIP6 ensemble is slightly decreased $\left(r^{2}=0.4\right)$. Moreover, we found that both Green's functions fail to reproduce CMIP6 $\Delta \lambda$ (not shown), even though they largely capture $\Delta \lambda$ in CMIP5 models (Figs. 6c,d). Multiple factors may contribute to the inability of the CAM4/CAM5 Green's functions to capture the behavior of CMIP6 models, and we consider two of them here.

First, we consider the possibility that the CAM4/ CAM5 Green's functions cannot capture feedback changes in the CMIP6 models, even assuming that the radiative response to SST patterns remain linear (section 4a). That is, the CMIP6 models may be systematically different from the CMIP5 models from which the Green's functions are built. One example is the modifications made to extratropical clouds in CMIP6 models, whose feedbacks have strengthened in CMIP6 owing to changes in their sensitivities to local environmental conditions (Zelinka et al. 2020). These changes may give rise to a different dependence of cloud feedbacks on SST pattern, presumably with stronger cloud radiative response to Southern Ocean warming. In this case, the global TOA radiation change may no longer be dominated by the tropical warm-pool warming as seen in CAM4 Green's function for example (see Dong et al. 2019, their Fig. 11), but could instead also be strongly influenced by the Southern Ocean warming. As a result, the delayed Southern Ocean warming would yield a stronger pattern effect on the cloud feedback (i.e., a greater positive $\Delta \lambda_{\mathrm{CLD}}$ ). Indeed, the Southern 


\section{CMIP5}

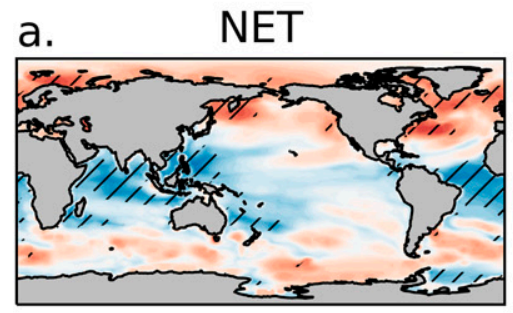

C.
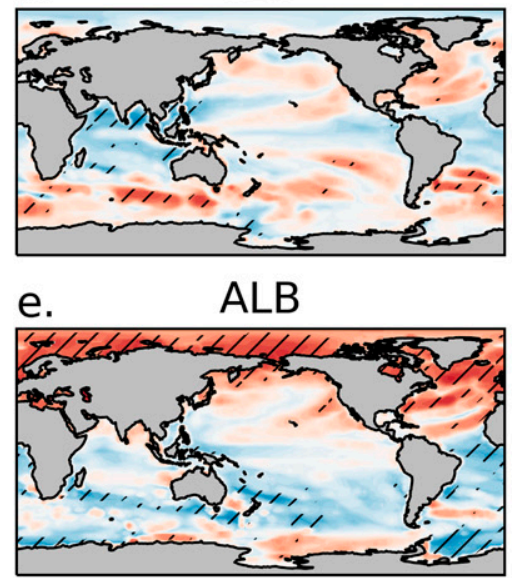

g.
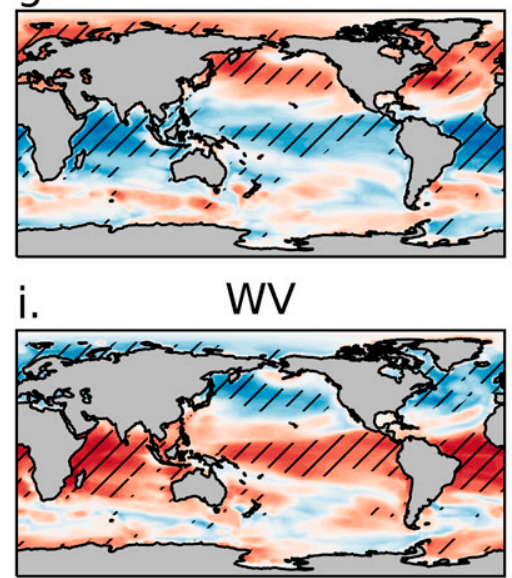

CMIP6

b.

NET

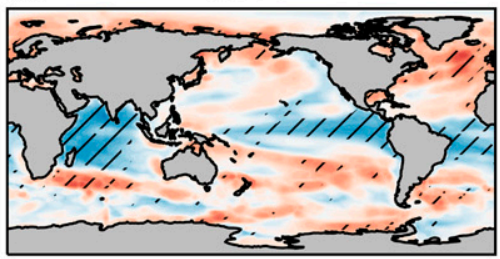

d. $\quad$ CLD

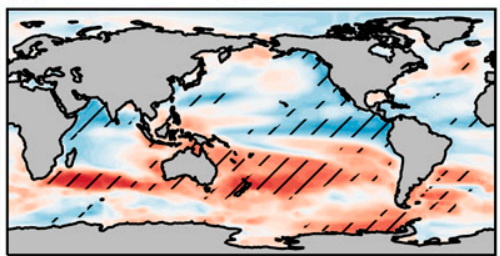

f. ALB

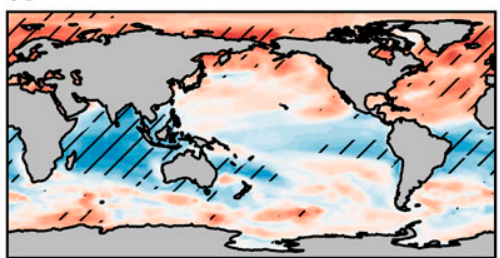

h. LR
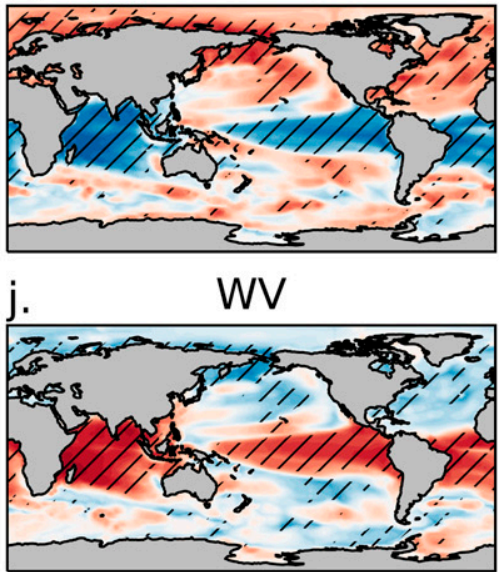

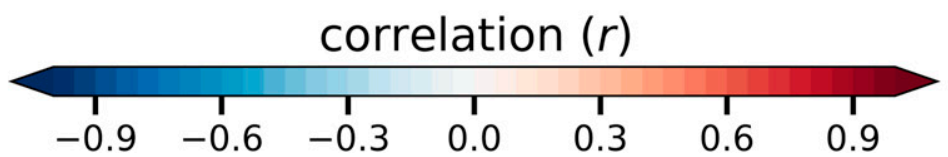

FIG. 9. Correlation coefficients $(r)$ for local regression of global-mean $\Delta \lambda$ against local $\Delta \mathrm{SST}^{*}$ (local SST warming rate relative to global-mean SST change) across (left) CMIP5 models and (right) CMIP6 models for (a),(b) net $\Delta \lambda$, (c),(d) cloud $\Delta \lambda$, (e),(f) surface-albedo $\Delta \lambda$, (g),(h) lapse rate $\Delta \lambda$, and (i),(j) water vapor feedback. Hatching marks grids where correlations are significant (i.e., $p<0.05$ ). 
Ocean is highlighted in the CMIP6's result in Fig. 9d with a stronger positive correlation, suggesting a stronger sensitivity of cloud feedback on the Southern Ocean warming rate. If this is the case, new Green's functions with up-to-date GCMs may better capture the causes of feedback changes in CMIP6 models.

Apart from extratropical clouds, changes in CMIP6 models may also yield a different radiative response to the equatorial eastern Pacific, where delayed warming seems to drive a negative $\Delta \lambda$ corresponding to a strengthening of global-mean (negative) feedback over time (Fig. 9b). However, there also remains a possibility that the correlation between the equatorial eastern Pacific warming and $\Delta \lambda$ is not causal but comes about through correlations between the eastern Pacific and $\mathrm{SH}$ extratropical warming rates, for instance. Specific mechanisms need to be further uncovered.

A second possibility comes from the potential nonlinear state dependence of feedbacks in the CMIP6 models, in which case the Green's functions can no longer apply as they rely on linear estimation. In particular, we consider a well-documented nonlinearity in the extratropical mixed-phase cloud feedback. The negative mixed-phase cloud feedback arises from the brightening of the clouds as they become increasingly composed of liquid droplets with warming. Therefore, it depends on the mean-state of ice/liquid fraction of the clouds, with more ice in the initial state leading to a stronger negative-feedback with warming (Tsushima et al. 2006; Storelvmo et al. 2015; McCoy et al. 2015). Many CMIP6 models now have higher climatological cloud liquid water fractions, in better agreement with observations (Bodas-Salcedo et al. 2019; Gettelman et al. 2019; Zelinka et al. 2020). Bjordal et al. (2020, manuscript submitted to Nat. Geosci.) shows that in CESM2, with the inclusion of a new mixed-phase ice nucleation scheme, the negative mixed-phase cloud feedback weakens with warming from the first 15 years to the last 15 years of abrupt $4 \times \mathrm{CO} 2$ simulation, particularly over the Southern Ocean, as the amount of ice decreases allowing for no further phase change to happen (see their Fig. 3). This weakening toward longer time scales in their simulations leads to a positive $\Delta \lambda_{\mathrm{CLD}}$ over the Southern Ocean, which is primarily driven by the nonlinear state dependence rather than by the pattern effect. If this case holds more generally across the CMIP6 models, the nonlinear state dependence of $\Delta \lambda_{\mathrm{CLD}}$ on the Southern Ocean warming may never be captured by any Green's functions, as the method relies on linear estimation.

In summary, we found the CMIP5 and CMIP6 ensembles on average highlight different regions where surface warming can influence the magnitude of global- mean $\Delta \lambda$ (Fig. 9). In CMIP5, intermodel differences in $\Delta \lambda$ are overall driven by intermodel differences in the surface warming rates over the west Pacific warm-pool region, where surface warming has strong remote impact on global TOA radiation changes (Dong et al. 2019). In CMIP6, intermodel differences in $\Delta \lambda$ (and the cloud component $\Delta \lambda_{\mathrm{CLD}}$ in particular) appear to have more contributions from SH extratropical warming and tropical eastern Pacific warming. Specific physical mechanisms are under investigation. Here we speculate that the stronger sensitivity of feedbacks on the delayed extratropical warming may result either from a stronger pattern effect (stronger cloud radiative response to surface warming in this region) or from a nonlinear state dependence of extratropical cloud feedback on the mean state of the liquid fraction in the clouds.

\section{Conclusions}

In this study, we investigated the changes in radiative feedbacks over time and their contributions to climate sensitivity from abrupt $4 \times \mathrm{CO} 2$ simulations within 24 CMIP5 GCMs and 29 CMIP6 models. Comprehensive comparisons were made between the two CMIP generations and between individual models. To examine the time variation of feedbacks, we derived feedback parameters from the Gregory regressions between the net TOA radiation imbalance and surface air temperature change over years $1-20$ as $\lambda_{1-20}$ and years $21-150$ as $\lambda_{21-150}$, and use $\Delta \lambda\left(=\lambda_{21-150}-\lambda_{1-20}\right)$ to represent the feedback changes over time.

We found that on average the effective ECS derived from the regression is higher and $\Delta \lambda$ is smaller in CMIP6 relative to CMIP5. We then evaluated the correlation between $\mathrm{ECS}_{21-150}$ (derived from years 21-150; featuring long-term response) and $\mathrm{ECS}_{1-20}$ (derived from years 1-20; featuring fast response governed primarily by $\left.\lambda_{1-20}\right)$. The correlation $\left(r^{2}\right)$ is 0.69 for CMIP5 and 0.70 for CMIP6, suggesting that the variance in ECS (as estimated by $\left.\mathrm{ECS}_{21-150}\right)$ is dominated by the differences in radiative response on the fast time scale, rather than the differences in $\Delta \lambda$. This also explains the fact that a greater $\Delta \lambda$ generally leads to a greater effective ECS within individual climate models, yet the higher effective ECS in the CMIP6 models occurs despite smaller $\Delta \lambda$. We also compared the ECS-to-ECS ${ }_{\text {hist }}$ ratio be-

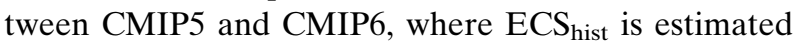
from years $2-50$ of abrupt $4 \times \mathrm{CO} 2$ simulations as an analog for historical warming. We found the difference in feedback estimates between the short-term abrupt $4 \times \mathrm{CO} 2$ (as the proxy for historical energy budget) and the longterm abrupt $4 \times \mathrm{CO} 2$ (as the proxy for equilibrium state) is on average smaller in CMIP6, and the CMIP6-mean 


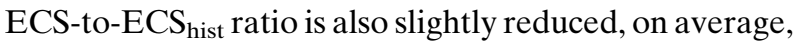
relative to CMIP5, suggesting a weaker forced pattern effect in CMIP6 abrupt $4 \times \mathrm{CO} 2$ simulations. Further work employing fully coupled historical simulation and RFMIP simulations are expected to provide a more accurate estimate on historical energy budget and the role of unforced pattern effect by internal variability over the historical period.

Although the spread in $\Delta \lambda$ contributes less to the spread in ECS than does atmospheric model physics, understanding the magnitude of $\Delta \lambda$ and the pattern effect is still of a great importance to constrain ECS on longer time scales. By comparing the multimodel mean $\Delta \lambda$ in the CMIP5 and CMIP6 models, we see great similarities in the spatial patterns of $\Delta \lambda$, highlighting the cold tongue regions with delayed warming. An overall smaller ensemble-mean $\Delta \lambda$ in the CMIP6 models is primarily due to the difference in surface-albedo feedback over the Arctic. While the positive Arctic surface-albedo feedback generally strengthens with time in CMIP5, it weakens over time in CMIP6, compensating the globalmean change in surface-albedo feedback. This is caused primarily by changes in surface warming patterns in CMIP6, which feature rapid Arctic warming on the fast time scale followed by slow Arctic warming on the slow time scale. But we caution that the differences between ensemble-mean $\Delta \lambda$ are not statistically significant given the large spread across models, and the results may be subject to change as more models come in.

Because both model physics and surface warming patterns are important for driving $\Delta \lambda$, we employ Green's functions to isolate their contributions and investigate why individual models produce different $\Delta \lambda$. The Green's functions used in this study are derived from two GCMs, which intrinsically represent the given model physics of CAM4 or CAM5 but can be independently applied to different SST anomaly patterns. When applied to the CMIP5 models, the Green's functions reproduce $\Delta \lambda$ well but cannot capture $\lambda_{1-20}$, suggesting that $\Delta \lambda$ is primarily set by the differences in warming patterns, while $\lambda_{1-20}$ is presumably determined by the differences in model physics. Building upon Dong et al. (2019), the spread in $\Delta \lambda$ is found to be well correlated with the change in the warm-pool warming ratio, defined as the relative ocean warming from warm-pool ascent regions to global-mean surface air warming. Across CMIP5 models, this simple metric is able to explain over $60 \%$ variance of $\Delta \lambda$. Models showing greater $\Delta \lambda$ generally have west Pacific warmpool regions warming up more quickly than the rest of world oceans on the fast time scale, but more slowly on longer time scales. This transition, on the other hand, is less significant in models that produce smaller $\Delta \lambda$. Regression of global-mean $\Delta \lambda$ against local warming rates also highlights the west Pacific warm-pool regions as the dominant control driving $\Delta \lambda$ variance across CMIP5 models, consistent with recent observations identifying the warm-pool as a key region controlling global radiation (e.g., Fueglistaler 2019).

However, the correlation analysis across CMIP6 models show a different spatial distribution, with $\mathrm{SH}$ extratropics and equatorial eastern Pacific being highlighted in addition to the west Pacific warm-pool regions, suggesting that the CMIP6 values of $\Delta \lambda$ may not be dominated by tropical warm-pool warming. The specific mechanism needs to be further uncovered; we speculate here that it may be partly attributable to a stronger sensitivity of extratropical clouds to surface warming. Future studies employing Green's function approach built from the CMIP6 models may bring more insights on investigating the pattern effect within the latest generation of GCMs, but will have limitations in the case that nonlinear state dependence of feedbacks also contributes to the changes in feedbacks with time.

Acknowledgments. We thank Stephen A. Klein and Masahiro Watanabe for insightful discussions, and thank the editor Isaac Held and three anonymous reviewers for constructive comments. We acknowledge the World Climate Research Programme, which, through its Working Group on Coupled Modelling, coordinated and promoted CMIP6. We thank the climate modeling groups for producing and making available their model output, the Earth System Grid Federation (ESGF) for archiving the data and providing access, and the multiple funding agencies who support CMIP6 and ESGF. YD, KCA, and $\mathrm{CP}$ were supported by National Science Foundation Grant AGS-1752796. MDZ's work was supported by DOE's Regional and Global Model Analysis Program and was performed under the auspices of the U.S. Department of Energy under Contract DE-AC5207NA27344. DSB was supported by the Tamaki Foundation. CZ was supported by NSFC 41875095. TA was supported by the Met Office Hadley Centre Climate Programme funded by Department for Business, Energy and Industrial Strategy (BEIS) and Department for Environment, Food and Rural Affairs (Defra).

\section{REFERENCES}

Andrews, T., and M. J. Webb, 2018: The dependence of global cloud and lapse rate feedbacks on the spatial structure of tropical Pacific warming. J. Climate, 31, 641-654, https:// doi.org/10.1175/JCLI-D-17-0087.1.

, J. M. Gregory, and M. J. Webb, 2015: The dependence of radiative forcing and feedback on evolving patterns of surface temperature change in climate models. J. Climate, 28, 16301648, https://doi.org/10.1175/JCLI-D-14-00545.1. 
— and Coauthors, 2018: Accounting for changing temperature patterns increases historical estimates of climate sensitivity. Geophys. Res. Lett., 45, 8490-8499, https://doi.org/10.1029/ 2018 GL078887.

_ , and Coauthors, 2019: Forcings, feedbacks, and climate sensitivity in HadGEM3-GC3.1 and UKESM1.J. Adv. Model. Earth Syst., 11, 4377-4394, https://doi.org/10.1029/2019MS001866.

Armour, K. C., 2017: Energy budget constraints on climate sensitivity in light of inconstant climate feedbacks. Nat. Climate Change, 7, 331-335, https://doi.org/10.1038/nclimate3278.

— C. M. Bitz, and G. H. Roe, 2013: Time-varying climate sensitivity from regional feedbacks. J. Climate, 26, 4518-4534, https://doi.org/10.1175/JCLI-D-12-00544.1.

Bader, D. C., R. Leung, M. Taylor, and R. B. McCoy, 2019: E3SMProject E3SM1.0 model output prepared for CMIP6 CMIP, version 20191230. Earth System Grid Federation, accessed December 2019, https://doi.org/10.22033/ESGF/CMIP6.2294.

Bloch-Johnson, J., R. T. Pierrehumbert, and D. S. Abbot, 2015: Feedback temperature dependence determines the risk of high warming. Geophys. Res. Lett., 42, 4973-4980, https:// doi.org/10.1002/2015GL064240.

Block, K., and T. Mauritsen, 2013: Forcing and feedback in the MPI-ESM-LR coupled model under abruptly quadrupled $\mathrm{CO}_{2}$. J. Adv. Model. Earth Syst., 5, 676-691, https://doi.org/ 10.1002/jame.20041.

Bodas-Salcedo, A., J. P. Mulcahy, T. Andrews, K. D. Williams, M. A. Ringer, P. R. Field, and G. S. Elsaesser, 2019: Strong dependence of atmospheric feedbacks on mixed-phase microphysics and aerosol-cloud interactions in HadGEM3. J. Adv. Model. Earth Syst., 11, 1735-1758, https://doi.org/ 10.1029/2019MS001688.

Bony, S., and J.-L. Dufresne, 2005: Marine boundary layer clouds at the heart of tropical cloud feedback uncertainties in climate models. Geophys. Res. Lett., 32, L20806, https://doi.org/ 10.1029/2005GL023851.

- , and Coauthors, 2006: How well do we understand and evaluate climate change feedback processes? J. Climate, 19, 34453482, https://doi.org/10.1175/JCLI3819.1.

Boucher, O., S. Denvil, A. Caubel, and M. A. Foujols, 2018: IPSL IPSL-CM6A-LR model output prepared for CMIP6 CMIP, version 20191230. Earth System Grid Federation, accessed December 2019, https://doi.org/10.22033/ESGF/CMIP6.1534.

Caballero, R., and M. Huber, 2013: State-dependent climate sensitivity in past warm climates and its implications for future climate projections. Proc. Natl. Acad. Sci. USA, 110, 14162 14 167, https://doi.org/10.1073/pnas.1303365110.

Caldwell, P. M., M. D. Zelinka, K. E. Taylor, and K. Marvel, 2016: Quantifying the sources of intermodel spread in equilibrium climate sensitivity. J. Climate, 29, 513-524, https://doi.org/ 10.1175/JCLI-D-15-0352.1.

,-- , and S. A. Klein, 2018: Evaluating emergent constraints on equilibrium climate sensitivity. J. Climate, 31, 3921-3942, https://doi.org/10.1175/JCLI-D-17-0631.1.

Cao, J., and B. Wang, 2019: NUIST NESMv3 model output prepared for CMIP6 CMIP, version 20191230. Earth System Grid Federation, accessed December 2019, https://doi.org/10.22033/ ESGF/CMIP6.2021.

Ceppi, P., and J. M. Gregory, 2017: Relationship of tropospheric stability to climate sensitivity and Earth's observed radiation budget. Proc. Natl. Acad. Sci. USA, 114, 13 126-13131, https:// doi.org/10.1073/PNAS.1714308114.

_ , F. Brient, M. D. Zelinka, and D. L. Hartmann, 2017: Cloud feedback mechanisms and their representation in global climate models. Wiley Interdiscip. Rev.: Climate Change, $\mathbf{8}$, e465, https://doi.org/10.1002/WCC.465.

Danabasoglu, G., 2019: NCAR CESM2-WACCM model output prepared for CMIP6 CMIP piControl, version 20191230. Earth System Grid Federation, accessed December 2019, https://doi.org/10.22033/ESGF/CMIP6.10094.

—, D. Lawrence, K. Lindsay, W. Lipscomb, and G. Strand, 2019: NCAR CESM2 model output prepared for CMIP6 CMIP piControl, version 20191230. Earth System Grid Federation, accessed December 2019, https://doi.org/10.22033/ESGF/ CMIP6.7733.

Dessler, A. E., 2020: Potential problems measuring climate sensitivity from the historical record. J. Climate, 33, 2237-2248, https://doi.org/10.1175/JCLI-D-19-0476.1.

Dix, M., and Coauthors, 2019: CSIRO-ARCCSS ACCESS-CM2 model output prepared for CMIP6 CMIP piControl, version 20200401. Earth System Grid Federation, accessed April 2020, https://doi.org/10.22033/ESGF/CMIP6.4311.

Dong, Y., C. Proistosescu, K. C. Armour, and D. S. Battisti, 2019: Attributing historical and future evolution of radiative feedbacks to regional warming patterns using a Green's function approach: The preeminence of the western Pacific. J. Climate, 32, 5471-5491, https://doi.org/10.1175/JCLI-D-18-0843.1.

Dufresne, J.-L., and S. Bony, 2008: An assessment of the primary sources of spread of global warming estimates from coupled atmosphere-ocean models. J. Climate, 21, 5135-5144, https:// doi.org/10.1175/2008JCLI2239.1.

EC-Earth, 2019a: EC-Earth-Consortium EC-Earth3 model output prepared for CMIP6 CMIP piControl, version 20191230. Earth System Grid Federation, accessed December 2019, https://doi.org/10.22033/ESGF/CMIP6.4842.

, 2019b: EC-Earth-Consortium EC-Earth3-Veg model output prepared for CMIP6 CMIP, version 20191230. Earth System Grid Federation, accessed December 2019, https://doi.org/ 10.22033/ESGF/CMIP6.642.

Forster, P. M., T. Andrews, P. Good, J. M. Gregory, L. S. Jackson, and M. Zelinka, 2013: Evaluating adjusted forcing and model spread for historical and future scenarios in the CMIP5 generation of climate models. J. Geophys. Res. Atmos., 118, 11391150, https://doi.org/10.1002/jgrd.50174.

Fueglistaler, S., 2019: Observational evidence for two modes of coupling between sea surface temperatures, tropospheric temperature profile, and shortwave cloud radiative effect in the tropics. Geophys. Res. Lett., 46, 9890-9898, https://doi.org/ 10.1029/2019GL083990.

Gettelman, A., and Coauthors, 2019: High climate sensitivity in the Community Earth System Model version 2 (CESM2). Geophys. Res. Lett., 46, 8329-8337, https://doi.org/10.1029/ 2019GL083978.

Golaz, J., and Coauthors, 2019: The DOE E3SM coupled model version 1: Overview and evaluation at standard resolution. J. Adv. Model. Earth Syst., 11, 2089-2129, https://doi.org/ 10.1029/2018MS001603.

Goosse, H., and Coauthors, 2018: Quantifying climate feedbacks in polar regions. Nat. Commun., 9, 1919, https://doi.org/10.1038/ s41467-018-04173-0.

Gregory, J. M., and Coauthors, 2004: A new method for diagnosing radiative forcing and climate sensitivity. Geophys. Res. Lett., 31, L03205, https://doi.org/10.1029/2003GL018747.

, T. Andrews, P. Ceppi, T. Mauritsen, and M. J. Webb, 2020: How accurately can the climate sensitivity to $\mathrm{CO}_{2}$ be estimated from historical climate change? Climate Dyn., 54, 129157, https://doi.org/10.1007/S00382-019-04991-Y. 
Guo, H., and Coauthors, 2018: NOAA-GFDL GFDL-CM4 model output, version 20191230. Earth System Grid Federation, accessed December 2019, https://doi.org/10.22033/ESGF/CMIP6.1402.

Hajima, T., and Coauthors, 2019: MIROC MIROC-ES2L model output prepared for CMIP6 CMIP piControl, version 20191230. Earth System Grid Federation, accessed December 2019, https://doi.org/10.22033/ESGF/CMIP6.5710.

Haugstad, A. D., K. C. Armour, D. S. Battisti, and B. E. J. Rose, 2017: Relative roles of surface temperature and climate forcing patterns in the inconstancy of radiative feedbacks, Geophys. Res. Lett., 44, 7455-7463, https://doi.org/10.1002/ 2017GL074372.

Huang, Y., Y. Xia, and X. Tan, 2017: On the pattern of $\mathrm{CO}_{2}$ radiative forcing and poleward energy transport. J. Geophys. Res. Atmos., 122, $10578-10593$, https://doi.org/10.1002/ 2017JD027221.

Kay, J. E., and Coauthors, 2012: Exposing global cloud biases in the Community Atmosphere Model (CAM) using satellite observations and their corresponding instrument simulators. J. Climate, 25, 5190-5207, https://doi.org/10.1175/JCLI-D-1100469.1.

Krasting, J. P., and Coauthors, 2018: NOAA-GFDL GFDL-ESM4 model output prepared for CMIP6 CMIP piControl, version 20200401. Earth System Grid Federation, accessed April 2020, https://doi.org/10.22033/ESGF/CMIP6.8669.

Lewis, N., and J. Curry, 2018: The impact of recent forcing and ocean heat uptake data on estimates of climate sensitivity. J. Climate, 31, 6051-6071, https://doi.org/10.1175/JCLI-D-170667.1.

Marvel, K., G. A. Schmidt, R. L. Miller, and L. S. Nazarenko, 2016: Implications for climate sensitivity from the response to individual forcings. Nat. Climate Change, 6, 386-389, https:// doi.org/10.1038/nclimate2888.

- , R. Pincus, G. A. Schmidt, and R. L. Miller, 2018: Internal variability and disequilibrium confound estimates of climate sensitivity from observations. Geophys. Res. Lett., 45, 15951601, https://doi.org/10.1002/2017GL076468.

McCoy, D. T., D. L. Hartmann, M. D. Zelinka, P. Ceppi, and D. P. Grosvenor, 2015: Mixed-phase cloud physics and Southern Ocean cloud feedback in climate models. J. Geophys. Res. Atmos., 120, 9539-9554, https://doi.org/10.1002/2015JD023603.

Meraner, K., T. Mauritsen, and A. Voigt, 2013: Robust increase in equilibrium climate sensitivity under global warming. Geophys. Res. Lett., 40, 5944-5948, https://doi.org/10.1002/ 2013 GL058118.

NASA/GISS, 2018a: NASA-GISS GISS-E2.1G model output prepared for CMIP6 CMIP, version 20191230. Earth System Grid Federation, accessed December 2019, https://doi.org/ 10.22033/ESGF/CMIP6.1400.

, 2018b: NASA-GISS GISS-E2.1H model output prepared for CMIP6 CMIP, version 20191230. Earth System Grid Federation, accessed December 2019, https://doi.org/10.22033/ESGF/ CMIP6.1421.

Park, S., and J. Shin, 2019: SNU SAM0-UNICON model output prepared for CMIP6 CMIP piControl, version 20191230. Earth System Grid Federation, accessed December 2019, https://doi.org/10.22033/ESGF/CMIP6.7791.

Pincus, R., P. M. Forster, and B. Stevens, 2016: The Radiative Forcing Model Intercomparison Project (RFMIP): Experimental protocol for CMIP6. Geosci. Model Dev., 9, 3447-3460, https:// doi.org/10.5194/gmd-9-3447-2016.

Proistosescu, C., and P. J. Huybers, 2017: Slow climate mode reconciles historical and model-based estimates of climate sensitivity. Sci. Adv., 3, e1602821, https://doi.org/10.1126/ sciadv.1602821.

Ridley, J., M. Menary, T. Kuhlbrodt, M. Andrews, and T. Andrews, 2018: MOHC HadGEM3-GC31-LL model output prepared for CMIP6 CMIP, version 20191230. Earth System Grid Federation, accessed December 2019, https://doi.org/10.22033/ ESGF/CMIP6.419.

Rong, X., 2019: CAMS CAMS_CSM1.0 model output prepared for CMIP6 CMIP, version 20191230. Earth System Grid Federation, accessed December 2019, https://doi.org/10.22033/ ESGF/CMIP6.1399.

Rugenstein, M., and Coauthors, 2020: Equilibrium climate sensitivity estimated by equilibrating climate models. Geophys. Res. Lett., 47, e2019GL083898, https://doi.org/ 10.1029/2019GL083898.

Seferian, R., 2018: CNRM-CERFACS CNRM-ESM2-1 model output prepared for CMIP6 CMIP, version 20191230. Earth System Grid Federation, accessed December 2019, https:// doi.org/10.22033/ESGF/CMIP6.1391.

Seland, Ø., and Coauthors, 2019: NCC NorESM2-LM model output prepared for CMIP6 CMIP piControl, version 20191230. Earth System Grid Federation, accessed December 2019, https://doi.org/10.22033/ESGF/CMIP6.8217.

Sellar, A. A., and Coauthors, 2019: UKESM1: Description and evaluation of the UK Earth System Model. J. Adv. Model. Earth Syst., 11, 4513-4558, https://doi.org/10.1029/2019MS001739.

Silvers, L. G., D. Paynter, and M. Zhao, 2018: The diversity of cloud responses to twentieth century sea surface temperatures. Geophys. Res. Lett., 45, 391-400, https://doi.org/10.1002/ 2017 GL075583.

Soden, B. J., and I. M. Held, 2006: An assessment of climate feedbacks in coupled ocean-atmosphere models. J. Climate, 19, 3354-3360, https://doi.org/10.1175/JCLI3799.1.

Stevens, B., S. C. Sherwood, S. Bony, and M. J. Webb, 2016: Prospects for narrowing bounds on Earth's equilibrium climate sensitivity. Earth's Future, 4, 512-522, https://doi.org/ 10.1002/2016EF000376.

Storelvmo, T., I. Tan, and A. V. Korolev, 2015: Cloud phase changes induced by $\mathrm{CO}_{2}$ warming-A powerful yet poorly constrained cloud-climate feedback. Curr. Climate Change Rep., 1, 288-296, https://doi.org/10.1007/s40641-015-0026-2.

Swart, N. C., and Coauthors, 2019: CCCma CanESM5 model output prepared for CMIP6 CMIP, version 20191230. Earth System Grid Federation, accessed December 2019, https:// doi.org/10.22033/ESGF/CMIP6.3610.

Tang, Y., S., Rumbold, R. Ellis, D. Kelley, J. Mulcahy, A. Sellar, J. Walton, and C. Jones, 2019: MOHC UKESM1.0-LL model output prepared for CMIP6 CMIP, version 20191230. Earth System Grid Federation, accessed December 2019, https:// doi.org/10.22033/ESGF/CMIP6.1569.

Tatebe, H., and M. Watanabe, 2018: MIROC MIROC6 model output prepared for CMIP6 CMIP abrupt-4xCO2, version 20191230. Earth System Grid Federation, accessed December 2019, https://doi.org/10.22033/ESGF/CMIP6.5411.

Tsushima, Y., and Coauthors, 2006: Importance of the mixed-phase cloud distribution in the control climate for assessing the response of clouds to carbon dioxide increase: A multi-model study. Climate Dyn., 27, 113-126, https://doi.org/10.1007/ s00382-006-0127-7.

Voldoire, A., 2018: CNRM-CERFACS CNRM-CM6-1 model output prepared for CMIP6 CMIP, version 20191230. Earth System Grid Federation, accessed December 2019, https:// doi.org/10.22033/ESGF/CMIP6.1375. 
Volodin, E., and Coauthors, 2019: INM INM-CM4-8 model output prepared for CMIP6 CMIP piControl, version 20191230. Earth System Grid Federation, accessed December 2019, https://doi.org/10.22033/ESGF/CMIP6.5080.

Webb, M. J., and Coauthors, 2006: On the contribution of local feedback mechanisms to the range of climate sensitivity in two GCM ensembles. Climate Dyn., 27, 17-38, https://doi.org/ 10.1007/s00382-006-0111-2.

_ _ F. H. Lambert, and J. M. Gregory, 2013: Origins of differences in climate sensitivity, forcing and feedback in climate models. Climate Dyn., 40, 677-707, https://doi.org/10.1007/ s00382-012-1336-x.

— and Coauthors, 2015: The impact of parametrized convection on cloud feedback. Philos. Trans. Roy. Soc., A373, 20140414 https://doi.org/10.1098/rsta.2014.0414.

Wu, T., and Coauthors, 2018: BCC BCC-CSM2MR model output prepared for CMIP6 CMIP piControl, version 20191230. Earth System Grid Federation, accessed December 2019, https://doi.org/10.22033/ESGF/CMIP6.3016.

Yukimoto, S., and Coauthors, 2019: MRI MRI-ESM2.0 model output prepared for CMIP6 CMIP, version 20191230. Earth System Grid Federation, accessed December 2019, https:// doi.org/10.22033/ESGF/CMIP6.621.
Zelinka, M. D., C. Zhou, and S. A. Klein, 2016: Insights from a refined decomposition of cloud feedbacks. Geophys. Res. Lett., 43, 9259-9269, https://doi.org/10.1002/2016GL069917.

- T. A. Myers, D. T. McCoy, S. Po-Chedley, P. M. Caldwell, P. Ceppi, S. A. Klein, and K. E. Taylor, 2020: Causes of higher climate sensitivity in CMIP6 models. Geophys. Res. Lett., 47, e2019GL085782, https://doi.org/10.1029/2019GL085782.

Zhang, J., and Coauthors, 2018: BCC BCC-ESM1 model output prepared for CMIP6 CMIP piControl, version 20191230. Earth System Grid Federation, accessed December 2019, https://doi.org/10.22033/ESGF/CMIP6.3017.

Zhou, C., M. D. Zelinka, and S. A. Klein, 2016: Impact of decadal cloud variations on the Earth's energy budget. Nat. Geosci., 9, 871-874, https://doi.org/10.1038/ngeo2828.

,$- \ldots$, and ——, 2017: Analyzing the dependence of global cloud feedback on the spatial pattern of sea surface temperature change with a Green's function approach. $J$. $A d v$. Model. Earth Syst., 9, 2174-2189, https://doi.org/10.1002/ 2017MS001096.

Ziehn, T., and Coauthors, 2019: CSIRO ACCESS-ESM1.5 model output prepared for CMIP6 CMIP piControl, version 20200401. Earth System Grid Federation, accessed April 2020, https://doi.org/10.22033/ESGF/CMIP6.4312. 